\title{
INMIGRACIÓN LABORAL EN LA RIOJA 20I0*
}

\author{
F. Javier DÍEZ MORRÁS
}

Abogado del Ilustre Colegio de Abogados de La Rioja

MÁSTER UNIVERSITARIO EN MIGRACIONES INTERNACIONALES CONTEMPORÁNEAS

SUMARIO: I. Introducción. I.I. Inmigrantes y extranjeros. I.2. Un actual contexto de crisis económica. II. La población extranjera. III. Autorizaciones de residencia. IV. Situación laboral del inmigrante. IV.r. Situación laboral del extranjero antes de su partida hacia España. IV.2. Situación laboral inicial y actual en España. IV.3. Sectores de actividad. IV.4. Los inmigrantes según el tipo de ocupación. V. Afiliación a la Seguridad Social. V.r. Europeos-no europeos. V.2. Afiliación según régimen de cotización. V.3. Afiliación por actividad (Régimen general). VI. Contratación. VI.I. Tipos de contratación y sectores. VI.2. Contratación por procedencia geográfica. VII. Parados extranjeros en La Rioja. VIII. Conclusiones. IX. Bibliografía.

RESUMEN: La Comunidad Autónoma de la Rioja se ha visto afectada de forma especial en la última década por la llegada de un buen número de extranjeros, lo que ha provocado un significativo aumento de su población. Esto se ha debido a la existencia hasta 2007 de una situación económica propicia ligada especialmente a un sector económico, el de la construcción, lo que provocó la llegada de mano de obra no cualificada singularmente inmigrante. La actual situación económica, que está afectando de manera negativa a la oferta de trabajo y particularmente a los trabajadores extranjeros, ha frenado la llegada de éstos a nuestra región, si bien no se observa hasta el año 2010 una salida masiva huyendo de la situación de crisis.

PALABRAS ClAVE: inmigración, extranjeros, trabajo, La Rioja.

\section{LABOUR IMMIGRATION IN LA RIOJA IN $20 I 0$}

ABSTRACT: La Rioja has been affected in the last decade by the arrival of foreigners. This has caused a considerable increase in its population. This increase has been caused by the existence, until 2007, a favorable economic situation related to construction. The current economic situation, which is negatively affecting work and foreign workers, has slowed the arrival of foreigners to our region, although not seen a mass exodus fleeing the economic crisis.

KEYWORDS: inmigration, foreigners, work, La Rioja.

\footnotetext{
* El presente trabajo es un resumen del realizado en 20 io con la ayuda y patrocinio del Ministerio de Política Territorial y Administración Pública y la Delegación del Gobierno en La Rioja.
} 


\section{Introducción}

Las migraciones son un fenómeno social, jurídico, político y económico de primera magnitud en España y por tanto en La Rioja. En esta Comunidad Autónoma los porcentajes de presencia extranjera superan desde hace años la media nacional. La diferencia de desarrollo entre países, la interdependencia económica internacional, los avances en las telecomunicaciones y en los transportes, los conflictos bélicos generadores de refugiados y desplazados son algunos de los factores que provocan hoy movilidad de personas entre países.

La inmigración española de los últimos diez años ha tenido un carácter eminentemente laboral. Los extranjeros han venido a nuestro país a trabajar ocupando sectores abandonados por la mano de obra nativa o a los que ésta no ha podido dar respuesta. El incremento de la oferta para desarrollar trabajos en la construcción, los servicios hosteleros, turísticos y domésticos, la industria y la agricultura trajo un aumento del número de trabajadores extranjeros provocando un notable crecimiento económico del país y, de forma paralela, de los niveles de ocupación, de tributación y de cotización a la Seguridad Social. Sin embargo la inmigración ha ocupado sectores económicos más vulnerables a la crisis, por lo que los extranjeros han experimentado en las penosas consecuencias del período en el que nos encontramos.

\section{I.I. Inmigrantes y extranjeros}

Son varias las diferencias que la sociedad ha creado a la hora de dar contenido a los vocablos inmigrante y extranjero, siendo clave en ello el aspecto económico y laboral. Con ambos conceptos nos referimos a personas que se encuentran en España pero que nos son nacionales españoles. A partir de ese punto la sociedad ha ido otorgando a estos términos un significado distinto y la doctrina internacional no ha sido capaz de concretarlos y eliminar los matices peyorativos que se asocian al primero.

Por otro lado, para analizar el significado que se da a ambos debemos situarnos correctamente, pues esa diferenciación se produce siempre desde el punto de vista de la sociedad receptora. La denominación «inmigrante» ha adquirido en los últimos años un significado negativo, pues desde la sociedad receptora se ha señalado de esta manera al venido desde un país empobrecido o en vías de desarrollo, muchas veces política y socialmente inestable. El concepto tiene un claro matiz geográfico, político y social.

No obstante inmigrante es aquel que traslada su residencia de un lugar a otro, normalmente con una fuerte motivación laboral, con la intención de establecerse o afincarse permanente o indefinidamente en un nuevo país. Las circunstancias posteriores podrán llevar a una mayor o menor duración de esa nueva residencia, pero en principio el inmigrante desea iniciar un proyecto vital nuevo. La decisión de migrar está directamente relacionada con una mejora de las oportunidades de trabajo y de las condiciones económicas. El paro o unas malas condiciones laborales y sociales en el propio país ayudan a tomar la decisión de emigrar, aunque también existen otras circunstancias. Por ejemplo suelen ser los jóvenes con una formación superior a la media de sus países sus primeros protagonistas. También el factor femenino tiene gran importancia, pues la sociedad de origen normalmente no ofrece buenas oportunidades para las mujeres, caso por ejemplo del colectivo de dominicanas (Romero Valiente 2003). Por otro lado la existencia de responsabilidades familiares frena la decisión de emigrar, pero de igual manera la presencia de parte de la familia en el país de destino ayuda a abandonar el origen ejerciendo el derecho a la vida familiar mediante la reagrupación ${ }^{\mathrm{I}}$. También se tiene en cuenta la mayor o

\footnotetext{
${ }^{\text {I }}$ Sobre la reagrupación familiar y su gran importancia dentro del fenómeno migratorio ver: Aguilar Benítez de Lugo, M. y Grieder Machado, H.C. (200I), Lázaro González, I. (2002), Moliner Navarro, R.M. (200I y 2004),
} 
menor distancia geográfica y, en algunas ocasiones, la existencia o no de legislaciones favorecedoras de la recepción de trabajadores foráneos (Cuadrado Roura, Iglesias Fernández y Llorente Heras 2007, 2I-22).

Sin embargo en el concepto «extranjero» el peso del término recae en el matiz jurídico-internacional y no en el económico-laboral. Desde el punto de vista de la sociedad que lo recibe es una persona que también procede de otro país, no de otra región del país receptor, y por tanto también su estatus jurídico es diferente, pues no posee la nacionalidad de los naturales del país de recepción. Al igual que en el caso del llamado inmigrante hay traslado o desplazamiento, pero no es necesario que exista un deseo o intención de permanencia ni una motivación económica; un turista es por ejemplo considerado un extranjero, no un inmigrante.

La sociedad occidental está incidiendo especialmente en el lugar de origen para llevar a cabo esa diferenciación terminológica. Ha ayudado a ello el hecho de que los países europeos hayan regulado de diferente manera el estatus jurídico de los extranjeros procedentes de países de la UE y de los extranjeros procedentes de terceros países ${ }^{2}$. La diferencia de derechos y obligaciones entre ambos colectivos, a favor claramente de los primeros, ha sido un factor de diferenciación. Así, para un sector de la población occidental será extranjero el que procede de territorios de un nivel económico similar o superior al país de recepción, y son inmigrantes los que llegan de países menos desarrollados o subdesarrollados. Esta distinción perjudica la imagen del inmigrante, menoscaba su dignidad y en algunos casos favorece la conculcación de sus derechos.

\section{I.2. Un actual contexto de crisis económica}

El presente trabajo ha sido realizado en 20Io, en un contexto económico excepcional impensable hace apenas tres años debido a la crisis económica mundial en la que nos encontramos. Este período crítico comenzó a manifestarse de forma clara en agosto de 2007 en Estados Unidos y seguidamente en el resto de Occidente 3 .

Distintos análisis señalan que la actual crisis es una consecuencia de las políticas ultraliberales llevadas a cabo en los últimos veinte años. La bajada del precio del dinero llevó a un cómodo acceso al crédito apoyado por las entidades bancarias y con ello a un endeudamiento generalizado de las clases medias y bajas estadounidenses, las cuales adquirieron bienes y servicios de consumo a crédito confiando en el alto valor de los inmuebles para garantizar sus créditos e hipotecas. Con la crisis de las hipotecas subprime en Estados Unidos se produjo el estallido de lo que se ha conocido comúnmente como «burbuja inmobiliaria», con una acelerada caída de precios inmobiliarios e impago de

Moya Escudero, M. (200I), Quirós Fons, A. (2008), Santolaya Machetti, P. (2004), Vargas Gómez-Urrutia, M. (2006) y Zabalo Escudero, E. (2008).

${ }^{2}$ En España la situación jurídica de los extranjeros procedentes de terceros países está regulada por la Ley Orgánica $4 / 2000$, de II de enero, sobre derechos y libertades de los extranjeros en España y su integración social. Esta ley ha experimentado varias reformas siendo las más importantes las establecidas por Ley Orgánica $8 / 2000$, de 22 de diciembre, Ley Orgánica I4/2003, de 20 de noviembre y Ley Orgánica 2/2009, de II de diciembre, siendo ésta la última hasta la fecha. El vigente reglamento de desarrollo de la ley fue aprobado por Real Decreto 2.393/2004, de 30 de diciembre, si bien a la fecha de cierre de este trabajo se está trabajando en un nuevo reglamento de desarrollo de la ley en su última redacción de 2009. En cuanto a la normativa reguladora de la situación de los ciudadanos miembros de la Unión Europea está vigente el Real Decreto 240/2007, de I6 de febrero, sobre entrada, libre circulación y residencia en España de ciudadanos de los Estados Miembros de la Unión Europea y de otros Estados Parte en el Acuerdo sobre Espacio Económico Europeo.

${ }^{3}$ La Biblioteca de Ciencias Jurídicas y Sociales de la Universidad de Oviedo ha preparado en 2009 el documento «Una bibliografía para comprender la crisis financiera». Se trata de una completa selección de publicaciones, páginas web y blogs de gran interés y utilidad acerca de la crisis económica actual, en la que se recogen las referencias más importantes sobre el tema. 
hipotecas. Todo ello llevó a una crisis financiera y especialmente de confianza. Una de las consecuencias más importantes ha sido la disminución del consumo. Provocó que países como España, especialmente afectado por la crisis inmobiliaria entrase en recesión en el tercer trimestre de 2008 . A comienzos de 2009 todo Occidente se encontraba en recesión; al finalizar 2008 los países de la OCDE habían disminuido en un I,5\% su PIB -el PIB español caía entonces un $0,7 \%^{4}-$. En España la crisis se manifestó de forma especial en el aumento del desempleo, factor que en nuestro país es singularmente sensible a la crisis, si bien en países como EE.UU. también experimentó un considerable incremento. De diciembre de 2007 a enero de 2009 perdió cerca de 3,6 millones de empleos, y ya en 2009 perdió otros 4,2 millones.

Los inmigrantes serán los más afectados por estas nuevas circunstancias. La mayor eventualidad de los contratos en este grupo de población hizo que en España fuesen los primeros que experimentaron las consecuencias de la crisis, o sea, la pérdida del empleo. Por otro lado los trabajos de los inmigrantes, puestos de menor cualificación, se encontraban directa o indirectamente ligados a la construcción o al sector inmobiliario, sectores protagonistas de la crisis y especialmente afectados, y también a los servicios, otro de los ámbitos que primero se resienten en períodos de crisis por estar muy unido al consumo. Son sectores donde la temporalidad del empleo es una de sus características. Finalmente también el sector industrial se vio afectado de forma directa desde finales de 2008 y principios de 2009 , siendo numerosos los expedientes de regulación de empleo especialmente en la industria automovilística (Pajares 20I0, I9).

En 2010 ha crecido ligeramente el PIB en países de la Unión Europea, siendo el caso más significativo el de Alemania. Sin embargo la Comisión Europea señalaba a finales de 2009 que países como Grecia, Irlanda, Portugal y España retrasarían su ritmo de crecimiento y que estarían especialmente afectados por el desempleo. El año 2009 terminó con una caída de PIB en España del 3,6\%, dato que se sumaba a una caída del PIB acumulada durante los siete trimestres anteriores. Según los datos ofrecidos por el Instituto Nacional de Estadística, en el tercer trimestre de 20Io España registró una levísima subida de su PIB, situándose la tasa interanual en el o,2\%5.

La actual situación económica no favorece al trabajador extranjero, el cual ha visto cambiar de forma radical las circunstancias en las que vino a España. En 2006, a un año del inicio de la crisis, los análisis sobre la inmigración y el mercado de trabajo insistían en que el gran desarrollo de la inmigración se debía al «enorme aumento del empleo generado por la economía española», que ya era calificado como «insólito» e «inédito en términos históricos», y también a las «dificultades de la mano de obra nativa para atender aquella oferta» (Oliver Alonso 2007, 46). Los profesores Aja y Arango (2007) incidían entonces en que los flujos de entrada de inmigrantes se habían mantenido en 2006 «sustentados en el fuerte ritmo de crecimiento que caracteriza a la economía española, en la vigorosa demanda de trabajo que del mismo resulta y en la cada vez más reducida oferta nativa de trabajo» (Aja y Arango 2007, I2). Este breve párrafo condensa de forma clara y fiel varias notas caracterizadoras del fenómeno migratorio español previo a la situación de crisis: considerable crecimiento económico del país, directa relación de la llegada de la emigración con la demanda laboral y escasa mano de obra española en general y en determinados sectores en particular.

\section{La población extranjera}

Las cifras de población extranjera de La Rioja nos hablan desde hace una década de un elevado índice de presencia inmigrante. En términos absolutos esta región ha alcanzado

\footnotetext{
${ }^{4}$ Los datos españoles en el Instituto Nacional de Estadística.

${ }^{5}$ Instituto Nacional de Estadística. www.ine.es.
} 
en el año 2010 la cifra de 46.680 extranjeros según los datos aportados por el Instituto Nacional de Estadística. A pesar de ser la Comunidad Autónoma menos poblada de España, si exceptuamos las Ciudades Autónomas de Ceuta y Melilla, supera en número total de extranjeros a Cantabria y Extremadura, acercándose a regiones mucho más pobladas como Asturias. Observando el porcentaje riojano y el del resto de las Comunidades se puede apreciar en mayor medida el peso de la inmigración en nuestra región, que alcanza en el mismo año 2010 el I4,48\% de la población total de La Rioja. Únicamente Baleares, la Comunidad Valenciana, Madrid, Murcia, Cataluña y levemente Canarias, la sobrepasan. Por otro lado hay que tener en cuenta que en regiones como Baleares y la Comunidad Valenciana tiene una especial importancia la presencia de extranjeros procedentes de la Unión Europea, cuyo motivo de estancia es normalmente vacacional. En definitiva, sin necesidad de entrar en otras consideraciones y observado las cifras de población extranjera de todas las regiones españolas podemos afirmar que el fenómeno migratorio es especialmente relevante en La Rioja.

Población extranjera por Comunidades Autónomas 2010

\begin{tabular}{|c|c|c|c|}
\hline & Españoles & Extranjeros & \% Extranjeros \\
\hline Andalucía & 7.666.919 & 704.056 & $8,4 \mathrm{I}$ \\
\hline Aragón & I.I74.009 & I73.086 & $\mathrm{I} 2,85$ \\
\hline Asturias & I.035.055 & 49.286 & 4,55 \\
\hline Baleares & 863.793 & 242.256 & $2 \mathrm{I}, 90$ \\
\hline Canarias & I.8II.I4O & $307 \cdot 379$ & $\mathrm{I} 4,5 \mathrm{I}$ \\
\hline Cantabria & 553.049 & 39.201 & 6,62 \\
\hline Castilla y León & 2.390 .017 & 169.498 & 6,62 \\
\hline Castilla-La Mancha & I.868.8I9 & 229.554 & IO,94 \\
\hline Cataluña & 6.313 .843 & I.I98.538 & 15,95 \\
\hline Comunidad Valenciana & $4.217 \cdot 947$ & 893.759 & 17,48 \\
\hline Extremadura & 1.067 .864 & $39 \cdot 356$ & 3,55 \\
\hline Galicia & 2.687 .983 & 109.670 & 3,92 \\
\hline Madrid & $5 \cdot 378.740$ & I.079.944 & 16,72 \\
\hline Murcia & I.220.II4 & $24 \mathrm{I} .865$ & $\mathrm{I} 6,54$ \\
\hline Navarra & 565.555 & 72.369 & $\mathrm{II}, 2 \mathrm{I}$ \\
\hline País Vasco & 2.038 .970 & 139.369 & 6,40 \\
\hline Rioja, La & $275 \cdot 735$ & 46.680 & $\mathrm{I} 4,48$ \\
\hline Ceuta & 76.584 & $3 \cdot 995$ & 4,96 \\
\hline Melilla & 67.161 & 8.873 & II, 67 \\
\hline
\end{tabular}

Fuente: Instituto Nacional de Estadística

El aumento de la población extranjera experimentado en España en los últimos ıoI2 años, y por consiguiente también en La Rioja, tiene notas de excepcionalidad y una clara especialidad con respecto a los flujos migratorios de los países del entorno europeo. Los elementos característicos de la inmigración en España serán en primer lugar la gran intensidad del fenómeno en poco más de una década, en segundo lugar la heterogeneidad de las nacionalidades de origen de los inmigrantes y finalmente el desigual impacto en el 
territorio nacional, con zonas especialmente afectadas -Madrid y todo el litoral mediterráneo especialmente, y en menor medida el Ebro, incluida La Rioja, y otras zonas agrícolas- (Bayona 2008, I34 y ss.). Por otro lado hay que destacar que esta llegada de inmigrantes ha variado la tendencia descendente que se empezaba a observar en los indicadores de población de nuestro país.

La población española se ha visto incrementada en un I7,98\% entre I998 y 2010 , en números totales ha crecido en 7.I68.380 habitantes; por su parte la riojana ha experimentado un incremento relativo aún mayor, del 22,29\%, que en números totales es de 58.77I habitantes. Se puede observar que en La Rioja ha habido un mayor aumento de la población en términos porcentuales que en el resto del país. Se partió de una subida del 0,58\% en I999, porcentaje inferior al español -0,86\%-, y al final de la serie -año 2010nuestra región vuelve a estar en términos porcentuales por debajo del resto de España con un $0,22 \%$. Sin embargo entre 200 I y 2009 los incrementos relativos han sido mayores en La Rioja que en el resto del Estado con las leves excepciones de los años 2003 y 2007. Los datos confirman el crecimiento de la población total de España y de La Rioja durante los últimos doce años, en los cuales la inmigración ha tenido una especial incidencia.

Evolución de la población 1998-2010

\begin{tabular}{|c|c|c|c|c|c|c|}
\hline & \multicolumn{3}{|c|}{ ESPAÑA } & \multicolumn{3}{|c|}{ LA RIOJA } \\
\hline & Población & Increm. anual & $\%$ & Población & Increm. anual & $\%$ \\
\hline I998 & $39.852 .65 \mathrm{I}$ & --- & --- & 263.644 & --- & --- \\
\hline I999 & 40.202 .160 & $349 \cdot 509$ & 0,86 & 265.178 & I. 534 & 0,58 \\
\hline 2000 & $40.499 .79 \mathrm{I}$ & 297.631 & 0,74 & 264.178 & $-\mathrm{I} .000$ & $-I, O O$ \\
\hline $200 \mathrm{I}$ & 4I.II6.842 & 617.051 & $\mathrm{I}, 52$ & 270.400 & 6.222 & 2,36 \\
\hline 2002 & 4I.837.894 & 721.052 & $\mathrm{I}, 75$ & 28I.6I4 & II.2I4 & $4, \mathrm{I} 5$ \\
\hline 2003 & 42.717 .064 & 879.170 & $2, \mathrm{IO}$ & 287.390 & 5.776 & 2,05 \\
\hline 2004 & 43.197 .684 & 480.620 & $\mathrm{I}, \mathrm{I} 3$ & 293.553 & 6.163 & $2, \mathrm{I} 4$ \\
\hline 2005 & 44.108 .530 & 910.846 & $2, \mathrm{II}$ & 301.084 & $7.53 \mathrm{I}$ & 2,57 \\
\hline 2006 & 44.708 .964 & 600.434 & 1,36 & 306.377 & 5.293 & 1,76 \\
\hline 2007 & 45.200 .737 & 491.773 & I,IO & 308.968 & $2.59 \mathrm{I}$ & 0,85 \\
\hline 2008 & 46.157 .822 & 957.085 & $2, \mathrm{I} 2$ & $3 \mathrm{I} 7.5 \mathrm{OI}$ & 8.533 & 2,76 \\
\hline 2009 & 46.745 .807 & 587.985 & $\mathrm{I}, 27$ & 321.702 & $4.20 \mathrm{I}$ & $\mathrm{I}, 32$ \\
\hline 2010 & $47.021 .03 \mathrm{I}$ & 275.224 & 0,59 & 322.415 & 713 & 0,22 \\
\hline
\end{tabular}

Fuente: Instituto Nacional de Estadística

También en los empadronamientos se observa el crecimiento del número de extranjeros, tanto comunitarios como extracomunitarios. En España se pasó de tener 923.879 extranjeros empadronados en el año 2000, lo que significaba un porcentaje del $2,3 \%$ de la población total, a 5.747.734 en 20 Io, con un porcentaje del I2,2\%; la diferencia total es de 4.823 .855 empadronados más. En definitiva, se multiplicó casi por seis el 
número de inmigrantes empadronados, siendo por tanto una variación extraordinaria que no se ha repetido en ningún otro país de nuestro entorno ${ }^{6}$.

Las causas son varias si bien, como se ha señalado, la económica es la fundamental. Los extranjeros han venido a España, y por tanto a La Rioja, debido a la demanda de mano de obra no cualificada. Sectores como la construcción, con una dinámica ascendente en esta última década, han demandado durante estos años trabajadores y la población activa española no ha sido suficiente para cubrirla. Por otro lado en España tiene especial peso el sector turístico, también necesitado, por lo general, de mano de obra no muy cualificada. Tal y como muestra la evolución del Producto Interior Bruto, en España ha habido desde 1993 y hasta 2007 unas tasas de crecimiento continuas y altas que llegaron a ser mayores que el resto de países de la Unión Europea. La construcción ha sido aquí el principal sector que ha ayudado a ello, seguido de los servicios vinculados al turismo, siendo ambos sectores los que necesitan una mano de obra no especialmente cualificada. En el primer trimestre de I994 en España había I2.088.600 ocupados. Al aumentar el crecimiento la tasa de desempleo, que estaba en el $25,2 \%$, fue bajando incorporándose la mujer al mercado de trabajo. En 200I había ya alrededor de I5.800.000 ocupados y la tasa de desempleo había bajado al I0,9\%. Como señalan Pajares (2010, 25 y ss.) y Oliver (2007, 44 y ss.), este aumento del empleo se produjo entonces con población básicamente española, pues en ese período I994-200I sólo 500.700 nuevos ocupados fueron extranjeros, siendo sin embargo 3.277.300 los nuevos ocupados españoles.

Producto Interior Bruto español, I993-20I0. Datos a 3I de diciembre

\begin{tabular}{l|l|l|l|l|l|l|l|l|l}
$\mathbf{1 9 9 3}$ & 0,2 & $\mathbf{1 9 9 7}$ & 4,7 & $\mathbf{2 0 0 1}$ & 3,3 & $\mathbf{2 0 0 5}$ & 3,8 & $\mathbf{2 0 0 9}$ & $-3,0$ \\
\hline $\mathbf{1 9 9 4}$ & 2,5 & $\mathbf{1 9 9 8}$ & 4,0 & $\mathbf{2 0 0 2}$ & 2,7 & $\mathbf{2 0 0 6}$ & 4,0 & $\mathbf{2 0 1 0}$ & $-0, \mathrm{I}$ \\
\hline $\mathbf{1 9 9 5}$ & 2,4 & $\mathbf{1 9 9 9}$ & 5,3 & $\mathbf{2 0 0 3}$ & 3,2 & $\mathbf{2 0 0 7}$ & 3,2 & & \\
\hline $\mathbf{1 9 9 6}$ & 2,9 & $\mathbf{2 0 0 0}$ & 4,5 & $\mathbf{2 0 0 4}$ & 3,4 & $\mathbf{2 0 0 8}$ & $-\mathrm{I}, 4$ & & \\
\hline
\end{tabular}

Fuente: Instituto Nacional de Estadística

Entre los años 200I y 2007, si atendemos al PIB nacional, el crecimiento económico se mantuvo en niveles altos, no pudiendo la población nativa cubrir la gran demanda de mano de obra. Fue entonces cuando se produjo una masiva incorporación de extranjeros para ocupar los puestos de trabajo demandados. Ya hemos visto que tanto en España como en La Rioja fue en esos años cuando se produjo un mayor aumento poblacional vinculado directamente a la llegada de extranjeros. Los datos son de nuevo esclarecedores, en este nuevo período hubo un aumento de ocupados españoles de 2.I70.200 trabajadores, menos que en el período anterior, pero por otra parte hubo un espectacular incremento de ocupados extranjeros, nada menos que 2.365.700 (Pajares 20IO, 25 y ss. y Oliver 2007, 44 y ss.). No obstante es necesario destacar que, a pesar de lo anterior, el descenso del paro nativo se frenó de forma especial en los primeros años. En el período I994-200I el número de parados españoles bajó en 2.07I.500, sin embargo en el período $200 \mathrm{I}-2008$ solo descendió en I68.500, lo que nos habla de un problema en la

\footnotetext{
${ }^{6}$ Los datos del Padrón han de tomarse con ciertas precauciones. Uno de los problemas actuales es la lenta actualización de sus datos, pues las variaciones, altas y bajas no se actualizan de forma inmediata y simultánea en los padrones municipales afectados. Por otro lado un buen número de los inmigrantes que salen del país ya expulsados, ya de forma voluntaria, no informan de su salida, por lo que no son dados de baja hasta que esta nueva situación se gestiona de oficio por el ayuntamiento afectado ante la no renovación del empadronamiento por parte del extranjero.
} 
estructura económica española, la cual no es capaz de reducir el paro en momentos en los que la economía se desarrolla a niveles altos y demanda abundante mano de obra.

Así, sin la mano de obra extranjera no habría sido posible cubrir la demanda de ocupación existente justo antes del actual período de crisis económica; los inmigrantes han venido para ocupar puestos de trabajo abandonados por los españoles (Cuadrado, Iglesias y Llorente 2007,26$)$, lo que ha provocado que el trabajador español haya ascendido en la escala de cualificación laboral, con lo que la inmigración, contra la opinión generalizada, no ha afectado de forma negativa a los salarios de los trabajadores autóctonos (Pajares 2007). Sin la participación del trabajo inmigrante España, y también La Rioja, no habría crecido a los niveles que lo ha hecho en los últimos años (Pajares 2007, 2I-25), si bien es necesario preguntarse si el modelo económico desarrollado en este tiempo es el que el país necesitaba.

Extranjeros con autorización de residencia en España. A 3I de diciembre

\begin{tabular}{l|l|l|l}
2001 & I.109.060 & 2006 & 3.021 .808 \\
\hline 2002 & I.324.00I & 2007 & 3.979 .014 \\
\hline 2003 & I.647.01I & 2008 & 4.473 .499 \\
\hline 2004 & I.977.29I & 2009 & 4.791 .232 \\
\hline 2005 & 2.738 .932 & 2010 & 4.926 .608 \\
\hline
\end{tabular}

Fuente: Observatorio Permanente de la Inmigración. Secretaría de Estado de Inmigración y Emigración

Junto con el fundamental factor económico que se ha señalado como causa principal de la llegada de inmigrantes, también hay que considerar otros factores sociales y más concretamente familiares. Aquí entra en juego la reagrupación familiar, cuya regulación legal y reglamentaria ha ayudado a que los inmigrantes agrupasen a sus respectivas familias ejerciendo su derecho a vivir con la familia ${ }^{7}$.

\section{Autorizaciones de residencia}

La posibilidad de residir en nuestro país está supeditada a la solicitud y posterior concesión por parte del Ministerio de Trabajo y Asuntos Sociales de una autorización de residencia. La concesión de estas autorizaciones, reguladas en los capítulos II y III de la Ley de Extranjería, permite al extranjero de un tercer país no comunitario residir en España de forma regular inicialmente por un tiempo determinado. Dentro de estas autorizaciones se encuentran las de residencia y trabajo para desarrollar trabajos por cuenta propia y por cuenta ajena. Son concedidas a los extranjeros mayores de dieciséis años que cumplan con los requisitos legal y reglamentariamente establecidos ${ }^{8}$.

\footnotetext{
${ }^{7}$ La reagrupación familiar se encuentra regulada en los artículos i6 a i9 de la Ley Orgánica 4/2000, de II de noviembre, sobre derechos y libertades de los extranjeros en España y su integración social, en su vigente redacción aprobada por Ley Orgánica 2/2009, de II de diciembre. Como ya se ha señalado, a la espera de la aprobación de un nuevo reglamento de desarrollo de la ley al cierre de este trabajo, se encuentra en vigor el aprobado por Real Decreto 2.393/2004, de 30 de diciembre, que en sus artículos 38 al 44 desarrolla los anteriores artículos de la ley.
}

${ }^{8}$ Artículos 36 a 43 de la Ley Orgánica 4/2000. 
Se pueden observar los datos por Comunidades Autónomas referidos a los años 2008 y 2009 , pues al cierre de este trabajo no es posible conocer los de 2010. En un primer momento hay que destacar que hay un incremento muy visible de 317.733 autorizaciones de residencia. En ellas se incluyen tanto las referidas a extranjeros comunitarios como a extracomunitarios. A excepción de Aragón, todas las Comunidades Autónomas han visto incrementado el número de extranjeros.

A pesar de no tener los datos completos de 2010 sí se cuanta con los correspondientes a los tres primeros trimestres del año. Se puede adelantar que en España en 20I0, y a pesar de la situación económica actual, no se va a experimentar una disminución considerable de autorizaciones de residencia; todo lo contrario, a falta de un trimestre se puede afirmar que es muy probable que se vean superados, aunque ligeramente, los datos del año anterior. Los datos riojanos, si bien no se pueden extrapolar al resto del país, lo confirman. A 30 de septiembre de 2010 en nuestra región ya hay 523 autorizaciones de residencia más que en el año anterior. Se trata de un dato de gran relevancia teniendo en cuenta el contexto económico desfavorable en el que nos encontramos. La inmigración hacia España y hacia La Rioja en especial no disminuirá considerablemente en 20I0, año en el que el país ha sufrido un freno en su economía y un gran aumento del paro.

Extranjeros con autorización de residencia por Comunidades Autónomas. A 3I de diciembre

\begin{tabular}{|c|c|c|c|}
\hline & 2008 & 2009 & 2010 \\
\hline TOTAL ESPAÑA & 4.473 .499 & 4.791 .232 & 4.926 .608 \\
\hline Aragón & I73.937 & I70.273 & I79.I8I \\
\hline Asturias & 38.221 & 40.749 & 44.017 \\
\hline Baleares & 189.707 & 202.365 & 210.946 \\
\hline Canarias & 223.972 & $239 \cdot 3 \mathrm{I} 2$ & 250.033 \\
\hline Cantabria & $33 \cdot 7 \mathrm{I} 3$ & $36.16 \mathrm{I}$ & 38.440 \\
\hline Castilla-La Mancha & I92.948 & 204.517 & 2I4.9I9 \\
\hline Castilla y León & 170.262 & I75.5I6 & I84.834 \\
\hline Cataluña & 974.743 & 1.061 .079 & I.091.433 \\
\hline Com. Valenciana & 577.615 & 6I0.279 & 631.476 \\
\hline Extremadura & 39.566 & $4 \mathrm{I} .846$ & 45.680 \\
\hline Galicia & 85.618 & 90.738 & 93.545 \\
\hline Madrid & 796.979 & 880.613 & 849.087 \\
\hline Murcia & I97.805 & 210.103 & 213.432 \\
\hline Navarra & 63.072 & 64.687 & 65.714 \\
\hline País Vasco & 96.635 & 106.658 & II5. 838 \\
\hline La Rioja & $44 \cdot 322$ & 46.221 & 48.809 \\
\hline Ceuta & 4.045 & 4.492 & $4 \cdot 779$ \\
\hline Melilla & 6.929 & $7 \cdot 395$ & 8.605 \\
\hline
\end{tabular}

Fuente: Observatorio Permanente de la Inmigración Secretaría de Estado de Inmigración y Emigración 
Extranjeros con autorización de residencia según motivo de expedición

A 30 de septiembre de 2010

\begin{tabular}{|c|c|c|c|c|c|c|c|c|}
\hline \multicolumn{9}{|l|}{ ESPAÑA } \\
\hline TOTAL & Cta. aje. & $\begin{array}{l}\text { Cta. } \\
\text { prop. }\end{array}$ & $\begin{array}{l}\text { Res. no } \\
\text { lucrat. }\end{array}$ & Reagr. & Arraigo & Otros & $\begin{array}{l}\text { Res. larga } \\
\text { dur. }\end{array}$ & Comunit. \\
\hline $4 \cdot 754 \cdot 502$ & 485.916 & $7 \cdot 589$ & I86.60I & 203.589 & 67.778 & $2.65 \mathrm{I}$ & I. $44 \mathrm{I} .580$ & 2.358 .798 \\
\hline \multicolumn{9}{|l|}{ LA RIOJA } \\
\hline TOTAL & Cta. aje. & $\begin{array}{l}\text { Cta. } \\
\text { prop. }\end{array}$ & $\begin{array}{l}\text { Res. no } \\
\text { lucrat. }\end{array}$ & Reagr. & Arraigo & Otros & $\begin{array}{c}\text { Res. larga } \\
\text { dur. }\end{array}$ & Comunit. \\
\hline 46.744 & 2.804 & 72 & 899 & 4.005 & 573 & 7 & I6.759 & 21.625 \\
\hline
\end{tabular}

A 3I de diciembre de 2009

\begin{tabular}{|c|c|c|c|c|c|c|c|c|}
\hline \multicolumn{9}{|l|}{ ESPAÑA } \\
\hline TOTAL & Cta. aje. & $\begin{array}{l}\text { Cta. } \\
\text { prop. }\end{array}$ & $\begin{array}{l}\text { Res. no } \\
\text { lucrat. }\end{array}$ & Reagr. & Arraigo & Otros & $\begin{array}{l}\text { Res. larga } \\
\text { dur. }\end{array}$ & Comunit. \\
\hline 4.791.232 & 875.009 & I 4.527 & 248.903 & $229.22 \mathrm{I}$ & 79.433 & 2.885 & I.II2.064 & 2.229 .200 \\
\hline \multicolumn{9}{|l|}{ LA RIOJA } \\
\hline TOTAL & Cta. aje. & $\begin{array}{l}\text { Cta. } \\
\text { prop. }\end{array}$ & $\begin{array}{l}\text { Res. no } \\
\text { lucrat. }\end{array}$ & Reagr. & Arraigo & Otros & $\begin{array}{l}\text { Res. larga } \\
\text { dur. }\end{array}$ & Comunit. \\
\hline $46.22 \mathrm{I}$ & 6.392 & I7I & I. 205 & 4.I 45 & 755 & 4 & 13.102 & $\mathrm{I} 3 . \mathrm{IO} 2$ \\
\hline
\end{tabular}

A 3I de diciembre de 2008

\begin{tabular}{ccccccccc}
\hline ESPAÑA & \multicolumn{7}{c}{ Cta. } \\
\hline TOTAL & Cta. aje. & $\begin{array}{c}\text { Res. no } \\
\text { lucrat. }\end{array}$ & Reagr. & Arraigo & Otros & $\begin{array}{c}\text { Res. larga } \\
\text { dur. }\end{array}$ & Comunit. \\
\hline 4.473 .499 & 914.954 & I3.018 & 444.032 & -- & --- & $-\ldots$ & 969.048 & 2.132 .447 \\
\hline LA RIOJA & & & & & & & \\
\hline TOTAL & Cta. aje. & $\begin{array}{c}\text { Cta. } \\
\text { prop. }\end{array}$ & $\begin{array}{l}\text { Res. no } \\
\text { lucrat. }\end{array}$ & Reagr. & Arraigo & Otros & $\begin{array}{c}\text { Res. larga } \\
\text { dur. }\end{array}$ & Comunit. \\
\hline 44.322 & 6.996 & I45 & 5.269 & --- & --- & --- & II.430 & 20.482 \\
\hline
\end{tabular}




\begin{tabular}{|c|c|c|c|c|c|c|c|c|}
\hline \multicolumn{9}{|l|}{ ESPAÑA } \\
\hline TOTAL & Cta. aje. & $\begin{array}{l}\text { Cta. } \\
\text { prop. }\end{array}$ & $\begin{array}{l}\text { Res. no } \\
\text { lucrat. }\end{array}$ & Reagr. & Arraigo & Otros & $\begin{array}{l}\text { Res. larga } \\
\text { dur. }\end{array}$ & Comunit. \\
\hline 3.979 .014 & I.044.03I & I5.045 & 446.553 & --- & --- & --- & 851.589 & I. 621.796 \\
\hline \multicolumn{9}{|l|}{ LA RIOJA } \\
\hline TOTAL & Cta. aje. & $\begin{array}{l}\text { Cta. } \\
\text { prop. }\end{array}$ & $\begin{array}{l}\text { Res. no } \\
\text { lucrat. }\end{array}$ & Reagr. & Arraigo & Otros & $\begin{array}{l}\text { Res. larga } \\
\text { dur. }\end{array}$ & Comunit. \\
\hline 39.025 & 9.606 & $16_{3}$ & 5.990 & --- & --- & --- & I0. 583 & I2.683 \\
\hline
\end{tabular}

Fuente: Informe trimestral 3/20Io. Secretaría de Estado de Inmigración y Emigración

Desde 2007 hasta 2010 las autorizaciones de residencia en La Rioja han pasado de 39.025 a 48.809 . En 2008 aumentaron en 7.7I9 con respecto al año anterior y en 2009 aumentaron en I.899 con respecto a 2008. En 2010 el aumento fue de 2.588 , por lo que se observa un nuevo incremento ligeramente superior al período anual anterior. En el resto del país también ha aumentado el número de autorizaciones entre los años 2007 y 20I0. El total de extranjeros con autorización de residencia alcanza este último año una cifra record de 4.926.608. Son datos relevantes teniendo en cuenta la evolución de la situación económica de España precisamente desde el año 2007. Los datos riojanos difieren en términos porcentuales de los españoles, lo que incide en las diferencias existentes entre la economía española y riojana y la distinta distribución laboral y sectorial de los trabajadores extranjeros.

Sin embargo es necesario bajar a los diferentes tipos de autorización de residencia. Un dato fundamental que nos acerca a la situación económica es el de las autorizaciones de residencia y trabajo por cuenta ajena. En La Rioja en el año 2007 se concedieron 9.606 autorizaciones, en 2008 bajaron a 6.996, en 2009 se consolidaron cerca de la cifra anterior con 6.392 , pero ya a 30 de septiembre de 2010 se observa una considerable ralentización, pues quedando sólo un trimestre para finalizar el año se quedaban en 2.804. El paulatino descenso de este tipo de autorizaciones, que son las que se conceden a los trabajadores asalariados, grueso de los trabajadores riojanos, es más que palpable. Los porcentajes son también esclarecedores, siendo en 2007 el 24,6r\% de las autorizaciones, mientras a 30 de septiembre de 2010 se quedaban en el 6,00\%.

El descenso se aprecia en el total del Estado, pues si en 2007 había I.044.03I autorizaciones de residencia y trabajo por cuenta ajena -un 26,24\% de las autorizaciones de residencia-, a 30 de septiembre de 2010 habían bajado más de la mitad quedándose en 485.916 - un 10,22\% del total-.

Las claves para analizar el aumento de las autorizaciones de residencia se encuentran en los datos sobre residencia de larga duración, hasta 2009 denominada residencia permanente, y en la residencia de los comunitarios. En La Rioja en 2007 había I0.583 residentes permanentes. Este colectivo irá aumentando año a año y a 30 de septiembre de 2010 se situaba en I6.759 residentes. El aumento se aprecia especialmente en el peso porcentual con respecto al total de residencias pues en 2007 era del 27,I2\% y sin terminar 20 Io llegaba al 35,85\%. Por su parte los comunitarios residentes eran en La Rioja I2.683. La incorporación rumana y búlgara a la Unión Europea provocó que en 2008 fuesen ya 20.482, que se convirtieron en 2010 en 21.625 residentes comunitarios. Porcentualmente se pasó desde el $32,50 \%$ hasta el 46,26\%. Vemos cómo con el paso del tiempo los extranjeros van engrosando el grupo de los residente permanentes. El grupo de 
los extranjeros residentes permanentemente no se ve tan afectado por una situación económica adversa, pues a partir de la obtención de la autorización administrativa para residir de forma permanente en España, que es a los cinco años de haber obtenido su primera autorización de residencia y trabajo, no deben aportar documentación que acredite su situación económica, o sea no necesitan aportar un contrato de trabajo en vigor. La situación de desempleo no les afecta por tanto en su situación administrativa, por lo que un extranjero con ausencia de trabajo no deviene en situación irregular y por tanto no tiene por qué abandonar nuestro país9.

En España se experimenta un aumento porcentual total de extranjeros con residencia de larga duración muy parecido al riojano. No ocurre lo mismo con los comunitarios. En La Rioja es mayor el incremento porcentual de autorizaciones para este colectivo entre 2007 y 2010 . Se debe de nuevo al importante peso de la inmigración rumana en esta región.

\section{Situación laboral del inmigrante}

\section{IV.r. Situación laboral del extranjero antes de su partida hacia España}

La difícil situación laboral del inmigrante en su país de origen ha tenido una especial importancia en su decisión de partir hacia Occidente y en particular hacia España. A esa situación hay que sumar en primer lugar la demanda de trabajo existente tanto en nuestro país como en La Rioja. En segundo lugar, y en el caso de los latinoamericanos, también ha influido la proximidad cultural e idiomática con España. En menor medida, especialmente en los últimos años, ha tenido una singular relevancia la necesidad de realizar una reagrupación familiar. En definitiva, ha sido la pujante situación económica de nuestro país la que ha hecho que el inmigrante, una vez tomada la decisión de salir de su país de origen, se haya decantado por venir aquí en lugar de cualquier otro país europeo.

La Encuesta Nacional de Inmigrantes de 2007 (ENI) ${ }^{\text {Io }}$ nos indica que son alrededor de una tercera parte de los inmigrantes que habían venido a España los que partían de una situación originaria de desempleo en su país de origen; los datos generales del país, y los particulares de nuestra región, son muy parecidos, en concreto el 30,7\% de los extranjeros en La Rioja y el 3I,2\% para toda España manifestaron que provenían de una situación de desempleo. Por otro lado hay que destacar que más de la mitad son asalariados. Si se suman los que en su país eran asalariados tanto del sector privado como del público suman el 58,8\% en La Rioja y el 53,7\% en España. Al no ser propietarios de sus propios negocios, ya como empresarios, ya como otros trabajadores autónomos, los extranjeros asalariados tienen mayor facilidad para iniciar un movimiento migratorio y romper con su situación laboral previa, una situación que hemos de entender en la mayoría de los casos como insostenible.

\footnotetext{
${ }^{9}$ La adquisición de la autorización de residencia de larga duración y sus requisitos están regulados en los artículos Io y 32 de la Ley Orgánica 4/2000, de iı de enero; y artículos 7 I a 74 del Real Decreto 2.393/2004, de 30 de septiembre.

Io Los datos de la Encuesta Nacional de Inmigrantes se pueden consultar en la página web del Instituto Nacional de Estadística. Un buen análisis de los mismos en Colectivo IOÉ y Fernández M. (2OIO).
} 
Porcentaje de inmigrantes según su situación laboral antes de llegar a España (2007)

\begin{tabular}{lcc} 
& ESPAÑA & LA RIOJA \\
\hline No sabe su situación profesional & O,I & O,O \\
\hline Otra situación & 2,0 & I,I \\
\hline Ayuda familiar & I,9 & 2,4 \\
\hline Miembro de cooperativa & 0,2 & 0,3 \\
\hline Empresario & 2,7 & I,0 \\
\hline Trabajador independiente sin asalariados & 8,3 & 5,6 \\
\hline Asalariado del sector privado & 43,5 & 48,0 \\
\hline Asalariado del sector público & I0,2 & I0,8 \\
\hline No ha trabajado o no sabe & $3 \mathrm{I}, 2$ & 30,7 \\
\hline
\end{tabular}

Fuente: Encuesta Nacional de Inmigrantes 2007

IV.2. Situación laboral inicial y actual en España

En el siguiente apartado se observa la variación en la situación laboral del inmigrante desde su llegada a España según los datos de la ENI 2007.

Los inmigrantes de acuerdo con su situación actual e inicial en España y La Rioja

\begin{tabular}{|c|c|c|c|c|}
\hline & ESPAÑA & $\%$ & LA RIOJA & $\%$ \\
\hline TOTAL & 4.526 .522 & & 34.795 & \\
\hline Menos de tres años de residencia & 1.076 .666 & 23,8 & 9.080 & 26,I \\
\hline \multicolumn{5}{|l|}{ Más de tres años de residencia y: } \\
\hline - Empleo distinto a su llegada a España pero mismo sector & 562.317 & $\mathrm{I} 2,4$ & 4.804 & $\mathrm{I} 3,8$ \\
\hline - Empleo distinto a su llegada a España pero distinto sector & I.048.39I & 23,2 & 10.452 & 30,0 \\
\hline - Mismo empleo que al venir a España & 658.384 & $\mathrm{I} 4,5$ & 4.073 & II,7 \\
\hline - Han tenido trabajo pero ahora no trabajan & 66I.I5I & $\mathrm{I} 4,6$ & 4.088 & II,7 \\
\hline - No trabajan ni han trabajado en España & 519.613 & II, 5 & 2.297 & 6,6 \\
\hline
\end{tabular}

Fuentes: Encuesta Nacional de Inmigrantes 2007 e Inmigrantes y Extranjeros en La Rioja. Año 2009

De la tabla anterior se pueden extraer varias conclusiones de gran interés. En primer lugar que el 23,8\% no llevaba viviendo en 2007 , año de realización de la ENI, más de tres años en España, lo que apoya la idea de que es en los años de mitad de la década cuando más inmigrantes llegaron. El porcentaje aún es mayor si nos ceñimos a La Rioja, donde más de una cuarta parte se encontraba en esa situación -26,I\%-. 
Por otro lado se aprecia una notable movilidad laboral de los extranjeros, pues de los que llevaban más de tres años en España sólo el I4,5\% permanecían en 2007 en el mismo empleo, sin embargo el $35,6 \%$ había cambiado de trabajo ya dentro de su mismo sector o fuera de él. En La Rioja la diferencia aún es mayor. El porcentaje de trabajadores que se mantenía en el mismo puesto de trabajo era solo del ıi,7\%, y a la par el $43,8 \%$ había cambiado de trabajo. Esto se debe a las características del trabajo inmigrante riojano, donde la construcción y la agricultura han tenido un peso especial entre los trabajadores extranjeros.

Si a los porcentajes anteriores sumamos los de los extranjeros que en el momento de realizar la encuesta no trabajaban, aunque antes sí lo habían hecho, obtenemos que para España se llega a un 50,2\% y en el caso de La Rioja 55,5\%. O sea, más de la mitad de los extranjeros que llevaban más de tres años en España o en La Rioja habían experimentado un cambio laboral, ya para modificar su puesto de trabajo cambiando o no de sector, ya para abandonarlo y no volver a trabajar. Estos datos confirman de nuevo las características del trabajo desempeñado por el colectivo inmigrante en La Rioja, su movilidad, temporalidad y precariedad.

Finalmente hay que señalar que el II,5\% de inmigrantes en toda España y el 6,6\% en La Rioja declaraban en 2007 que nunca habían trabajado. Aquí se han de incluir los menores de edad pero en edad de trabajar, y las mujeres reagrupadas que se encargan de las familias y no trabajan fuera de casa, así como los estudiantes.

\section{IV.3. Sectores de actividad}

La construcción aparece como la actividad laboral clave en La Rioja en el año 2007 según la ENI con 4.8I2 trabajadores inmigrantes de un total de I9.330, circunstancia que se repite a nivel nacional con 438.4I4 trabajadores de la construcción en ese año de un total de 2.269.092. Sin embargo analizando el porcentaje es mayor en nuestra Comunidad Autónoma, pues se sitúa en un $24,9 \%$, siendo del I9,3\% a nivel nacional. Por el contrario hay una perceptible variación al observar las siguientes actividades mayoritarias. En el caso riojano es la industria manufacturera, con 4.II9 trabajadores extranjeros y un porcentaje del 2I,3\% la segunda actividad más importante, siguiéndole los servicios domésticos -con 2.I45 extranjeros y un II,I\%-; detrás aparecen la hostelería -con I.946 extranjeros y un IO,I\%-y la agricultura -con 1.877 extranjeros y un 9,7\%-.

Sin embargo en el global de España, aunque hemos señalado que es también la construcción la actividad mayoritaria, le siguen por este orden la hostelería -298.315 extranjeros y un I3,I\%-, el comercio de reparación -287.I04 extranjeros y un 12,7\%-, la industria manufacturera -249.857 extranjeros y un II,O\%- y los servicios domésticos $2 \mathrm{I} 3.720$ extranjeros y un 9,4\%-. Hemos visto arriba que las actividades manufactureras tienen en La Rioja mayor peso entre los trabajadores extranjeros. Tampoco la presencia de extranjeros en la agricultura y la ganadería riojana se corresponde con un parecido nivel a escala nacional. Esta actividad es superada en el resto del país por las actividades inmobiliarias y las actividades de transporte y almacenamiento.

Aunque la actividad laboral mayoritaria desarrollada por los trabajadores extranjeros, la construcción, coincide en La Rioja y en España, si bien en nuestra región con porcentajes mayores, el resto de actividades importantes difieren. En La Rioja el trabajador extranjero está también ocupando casi de igual manera puestos de trabajo en la industria y, además de los servicios en el hogar y en la hostelería, destaca el sector agrícola. En el resto de España el trabajador extranjero se centra en el sector de la construcción, los servicios domésticos y turísticos y la industria. Los datos inciden en la existencia de una estructura económica y laboral distinta en La Rioja y en España. 
Sector de actividad de inmigrantes con más de tres años de residencia en España

\begin{tabular}{|c|c|c|c|c|}
\hline & ESPAÑA & $\%$ & LA RIOJA & $\%$ \\
\hline TOTAL & 2.269 .092 & & 19.330 & \\
\hline Agricultura, ganadería,... & II6.325 & $5, \mathrm{I}$ & г. 877 & 9,7 \\
\hline Pesca & 2.677 & O,I & ○ & 0,0 \\
\hline Industrias extractivas & 3.885 & 0,2 & $\circ$ & 0,0 \\
\hline Industria manufacturera & 249.857 & II,O & 4.II9 & $2 \mathrm{I}, 3$ \\
\hline Producción y distrib. de energía eléctrica, gas y agua & 6.794 & 0,3 & $\circ$ & 0,0 \\
\hline Construcción & $438.4 \mathrm{I} 4$ & 19,3 & $4.8 \mathrm{I} 2$ & 24,9 \\
\hline Comercio de reparación & 287.104 & $\mathrm{I} 2,7$ & I. $53 \mathrm{I}$ & 7,9 \\
\hline Hostelería & 298.315 & I3,I & I.946 & IO,I \\
\hline Transporte, almacenamiento & $\mathrm{I} 32.490$ & 5,8 & 688 & 3,6 \\
\hline Intermediación financiera & $20.59 \mathrm{I}$ & 0,9 & $\circ$ & 0,0 \\
\hline Activ. Inmobiliarias & 208.393 & 9,2 & 778 & 4,0 \\
\hline Admón. Pública & 36.601 & $\mathrm{I}, 6$ & 257 & $\mathrm{I}, 3$ \\
\hline Educación & 70.736 & $3, \mathrm{I}$ & 320 & $\mathrm{I}, 7$ \\
\hline Activid. sanitarias y veterinarias & 83.395 & 3,7 & $5 \mathrm{I} 4$ & 2,7 \\
\hline Otras activ. sociales & 95.187 & 4,2 & 342 & $\mathrm{I}, 8$ \\
\hline Actividades de los hogares & 213.720 & 9,4 & 2.145 & II,I \\
\hline Organismos extraterritoriales & 1.706 & $\mathrm{O}, \mathrm{I}$ & ० & 0,0 \\
\hline No sabe & 2.903 & $\mathrm{O}, \mathrm{I}$ & ० & 0,0 \\
\hline
\end{tabular}

Fuente: Encuesta Nacional de Inmigrantes 2007 e Inmigrantes y Extranjeros en La Rioja. Año 2009

IV.4. Los inmigrantes según el tipo de ocupación

En La Rioja el trabajador extranjero muestra una menor cualificación que los trabajadores extranjeros del resto del país. El 36,3\% de los trabajadores extranjeros no son cualificados, sin embargo en España ese porcentaje baja al 27,I\%, lo que incide en una mayor preparación teórica y profesional de los extranjeros a nivel nacional. Como hemos visto en tablas anteriores, los extranjeros en La Rioja trabajan en la construcción, como obreros en la industria y como peones en la agricultura, trabajos para los que no es necesaria una formación profesional especializada.

Este dato se ve corroborado con el análisis de los porcentajes de trabajadores con una capacitación técnica o que ocupan puestos de administración y/o dirección. En España esos cuatro apartados suman un 26,1\% de los puestos, sin embargo en La Rioja sólo alcanzan un exiguo $6,6 \%$. 
Porcentaje de inmigrantes con más de tres años de residencia según su ocupación en 2007

\begin{tabular}{lcc} 
OCUPACIÓN & ESPAÑA & LA RIOJA \\
\hline No sabe o FF.AA. & 0,2 & 0,7 \\
\hline Trabajador no cualificados & $27, \mathrm{I}$ & 36,3 \\
\hline Operadores de instalac. y maquin. y montador. & 7,0 & $\mathrm{I} 2,7$ \\
\hline Artesanos y trabajadores cualific. de las industr. & I9,I & 23,5 \\
\hline Trabajadores cualif. en la agricultura y pesca & I,3 & I,7 \\
\hline Trabajadores servicios de restauración & I9,3 & I8,5 \\
\hline Empleados administrativos & 5,3 & I,I \\
\hline Técnicos y profesionales de apoyo & 6,6 & I,0 \\
\hline Técnicos y profesionales científicos e intelect. & $8, \mathrm{I}$ & 2,6 \\
\hline Dirección de empresas y de Admones. Públicas & $6, \mathrm{I}$ & $\mathrm{I}, 9$ \\
\hline
\end{tabular}

Fuente: Encuesta Nacional de Inmigrantes 2007 e Inmigrantes y Extranjeros en La Rioja. Año 2009

\section{Afiliación a la Seguridad Social}

El análisis de la situación de alta en la Seguridad Social es una fuente importante para conocer la situación laboral del extranjero en La Rioja y sus características debido a la obligatoriedad para los trabajadores de estar en situación de alta en cualquiera de los regímenes contemplados por la legislación. A pesar de la validez de los datos de afiliación a la Seguridad Social hay que tener en cuenta la variación de la situación a lo largo de un año, sobre todo en determinados sectores como la agricultura o la construcción.

No obstante desde 2008 el Ministerio de Trabajo e Inmigración pública las medias de cada mes, que sin duda son un dato más apropiado para analizar la evolución anual, pues los datos relativos al último día del mes no reflejan en absoluto la situación real durante el mismo, sino sólo la situación de ese día en concreto.

Evolución de los afiliados medios de La Rioja en diciembre

\begin{tabular}{cccc} 
& TOTAL & EXTRANJEROS & \% EXTRANJEROS \\
\hline 2006 & I32.293 & I7.030 & I2,90\% \\
\hline 2007 & I35.226 & I8.984 & I4,00\% \\
\hline 2008 & I30.14I & I7.544 & 13,50\% \\
\hline 2009 & I25.969 & I6.892 & I3,41\% \\
\hline
\end{tabular}

Fuente: Ministerio de Trabajo e Inmigración 
Evolución de los afiliados totales en España y en La Rioja (a 3I de diciembre)

\begin{tabular}{|c|c|c|c|c|c|c|}
\hline & \multicolumn{3}{|c|}{ ESPAÑA } & \multicolumn{3}{|c|}{ LA RIOJA } \\
\hline & TOTAL & Extranj. & \% Extranj. & TOTAL & Extranj. & \% Extranj. \\
\hline I998 & I3.8I6.294 & $262.77 \mathrm{I}$ & $\mathrm{I}, 90$ & 95.535 & I. $4 \mathrm{I} 3$ & $I, 50$ \\
\hline I999 & I4 578.326 & 332.407 & 2,30 & IOI.093 & 2.068 & 2,00 \\
\hline 2000 & $\mathrm{I} 5.236 .2 \mathrm{I} 8$ & $45^{2.097}$ & 3,00 & I05.579 & 3.232 & 3,IO \\
\hline 2001 & I5.748.752 & 604.900 & 3,80 & I09.000 & 4.729 & 4,30 \\
\hline 2002 & I6.I88.390 & 829.395 & 5,IO & II2.406 & 6.755 & 6,00 \\
\hline 2003 & I6.589.56I & 923.218 & 5,60 & II7.987 & 9.017 & 7,60 \\
\hline 2004 & I7.I6I.920 & I.074.79I & 6,30 & I 20.426 & I0.176 & 8,50 \\
\hline 2005 & I8.I56.I82 & I. 688.598 & 9,30 & I27.393 & I5.I74 & II,9O \\
\hline 2006 & I8.770.259 & I. 823.974 & 9,70 & I30.803 & I6.332 & $\mathrm{I} 2,50$ \\
\hline 2007 & I9.I95.755 & I.981.106 & 10,30 & 133.607 & $\mathrm{I} 8.26 \mathrm{I}$ & $\mathrm{I} 3,70$ \\
\hline 2008 & I8.305.6I3 & I. 882.223 & 10,30 & $\mathrm{I} 28.36 \mathrm{I}$ & I6.802 & I3,IO \\
\hline 2009 & I7.640.0I8 & I. 8 II. 850 & 10,27 & I24.4I9 & I6.236 & 13,05 \\
\hline
\end{tabular}

Fuente: Ministerio de Trabajo e Inmigración

La tabla refleja la progresiva evolución de la presencia de trabajadores extranjeros en España y en La Rioja y el continuo aumento de su peso dentro del colectivo trabajador hasta 2007. Aunque los datos de 2010 ofrecerán mayor información, se observa que esa tendencia varía a partir de 2008 y se confirma en 2009 , produciéndose en ambos años descensos debido a la situación económica del país.

Bajando a los datos de La Rioja, el aumento porcentual ha sido más acusado que en el resto del país. Si en España se partió en I998 de un I,90\% de trabajadores extranjeros afiliados del total de los mismos, en La Rioja se partía de I,50\%. Al final del período que abarcamos el porcentaje ha pasado en España al I0,27\% y en La Rioja al 13,05\%. En resumen en España el peso de los extranjeros ha aumentado un 9,37\%, siendo en La Rioja del II,55\%. Sin nos quedamos en 2007, límite del período de crecimiento económico español y de aumento de las afiliaciones, el aumento en España es del 8,40\% y en La Rioja del $\mathrm{I} 2,20 \%$, siendo por tanto la diferencia más acusada. Estos datos nos hablan de una región especialmente receptiva a la inmigración desde el punto de vista laboral y que desde el año 2000 ha demandado y ofrecido más mano de obra a este grupo de población que buena parte de las regiones españolas.

El gran salto producido en 2005 , tanto en las afiliaciones españolas $(3,00 \%)$ como en las riojanas $(3,40 \%)$, se debe a que en ese año se produjo el proceso extraordinario de normalización de extranjeros que implicó el alta en la Seguridad Social de un buen número de trabajadores extranjeros que hasta ese momento se encontraban en situación laboral y administrativa irregular. El dato se corrobora al compararlo con las afiliaciones de trabajadores españoles. En este año el aumento de las afiliaciones de trabajadores españoles fue del 5,80\%, mientras que en el colectivo inmigrante fue de un espectacular 57,10\%.

Desde 2008 , año en el que ya se hace patente la disminución de afiliaciones a la Seguridad Social, la caída es mayor entre los extranjeros. En ese año las afiliaciones 
españolas cayeron un 4,80\% mientras que las de los trabajadores inmigrantes descendieron un 5,00\%. En La Rioja la diferencia fue mayor, pues entre los españoles descendió un $4,00 \%$ y entre los extranjeros un $8,00 \%$.

Por otro lado las estadísticas riojanas manifiestan una clara masculinidad de la inmigración riojana aunque hay una lenta tendencia a la disminución de esa diferencia. En 2006 el porcentaje de hombres afiliados a la Seguridad Social era del 66,4I\%, porcentaje que asciende en 2007 al haber aumentado en I. 375 el número de extranjeros, sin embargo en 2008, como consecuencia de la situación económica, se produce una disminución de I.633 afiliados, tendencia que se confirma en 2009 al seguir disminuyendo otros 538 afiliados.

Evolución de la afiliación extranjera por sexos (a 3 I de diciembre)

\begin{tabular}{|c|c|c|c|c|c|c|c|c|}
\hline \multirow[b]{3}{*}{2006} & \multicolumn{4}{|c|}{ ESPAÑA } & \multicolumn{4}{|c|}{ LA RIOJA } \\
\hline & $\mathrm{H}$ & $\% \mathbf{H}$ & M & $\% \mathrm{M}$ & $\mathrm{H}$ & $\% \mathrm{H}$ & M & $\% \mathrm{M}$ \\
\hline & I.105.082 & 60,59 & 718.892 & $39,4 \mathrm{I}$ & I0.846 & $66,4 \mathrm{I}$ & 5.486 & 33,39 \\
\hline 2007 & I.202.767 & $60,7 \mathrm{I}$ & 778.339 & 39,29 & $\mathrm{I} 2.22 \mathrm{I}$ & 66,92 & 6.040 & 33,08 \\
\hline 2008 & 1.088 .065 & $57,8 \mathrm{I}$ & 794.I48 & $4^{2, \mathrm{I} 9}$ & I0. 588 & 63,02 & $6.2 \mathrm{I} 4$ & 36,98 \\
\hline 2009 & I.023.729 & 56,50 & 788.I2I & 43,50 & 10.050 & 61,90 & 6.186 & $38, \mathrm{IO}$ \\
\hline
\end{tabular}

Fuente: Ministerio de Trabajo e Inmigración

V.I. Europeos-no europeos

Evolución de los afiliados europeos y no europeos en España y en La Rioja (a 3I de diciembre)

ESPAÑA

\begin{tabular}{|c|c|c|c|c|c|}
\hline & TOTAL & U. E. & NO U. E. & \% U. E. & \% NO U. E. \\
\hline 1998 & $262.77 \mathrm{I}$ & IOI. 387 & I6I. 384 & 38,6 & $6 \mathrm{I}, 4$ \\
\hline 1999 & 332.407 & 120.563 & 2II. 844 & 36,3 & 63,7 \\
\hline 2000 & 452.097 & I40.39I & 3гі.844 & $3 \mathrm{I}, \mathrm{I}$ & 68,9 \\
\hline 2001 & 604.900 & I57.394 & 447.506 & 26,0 & 74,0 \\
\hline 2002 & 829.395 & I77.393 & 652.002 & $2 \mathrm{I}, 4$ & 78,6 \\
\hline 2003 & 923.218 & 205.577 & $7 \mathrm{I} 7.64 \mathrm{I}$ & 22,3 & 77,7 \\
\hline 2004 & I.074.79I & 248.655 & 826.136 & $23, \mathrm{I}$ & 76,9 \\
\hline 2005 & I. $688.59^{8}$ & 284.I49 & I. 404.449 & $\mathrm{I} 6,8$ & 83,2 \\
\hline 2006 & I. 823.974 & 350.298 & I. 473.676 & I9,2 & 80,8 \\
\hline 2007 & I. 98 I..ाo6 & 672.087 & I.309.019 & 33,9 & 66,I \\
\hline 2008 & I. 882.223 & 633.001 & I. 249.222 & 33,6 & 66,4 \\
\hline 2009 & I. 8 II. 850 & 655.209 & I.I56.64I & 36,2 & 63,8 \\
\hline
\end{tabular}




\section{LA RIOJA}

\begin{tabular}{cccccc}
\hline & TOTAL & U. E. & NO U. E. & \% U. E. & \% NO U. E. \\
\hline $\mathbf{1 9 9 8}$ & I.4I3 & 388 & I.025 & 27,5 & 72,5 \\
\hline $\mathbf{1 9 9 9}$ & 2.068 & $5 \mathrm{I} 2$ & I.556 & 24,8 & 75,2 \\
\hline $\mathbf{2 0 0 0}$ & 3.232 & 748 & 2.484 & $23, \mathrm{I}$ & 76,9 \\
\hline $\mathbf{2 0 0 1}$ & 4.729 & 904 & 3.825 & I9,I & 80,9 \\
\hline $\mathbf{2 0 0 2}$ & 6.755 & 973 & 5.782 & I4,4 & 85,6 \\
\hline $\mathbf{2 0 0 3}$ & 9.017 & 2.407 & 6.610 & 26,7 & 73,3 \\
\hline $\mathbf{2 0 0 4}$ & I0.176 & 2.842 & 7.334 & 27,9 & $72, \mathrm{I}$ \\
\hline $\mathbf{2 0 0 5}$ & I5.I74 & 2.845 & I2.329 & I8,7 & $8 \mathrm{I}, 3$ \\
\hline $\mathbf{2 0 0 6}$ & I6.332 & 3.514 & I2.818 & $2 \mathrm{I}, 5$ & 78,5 \\
\hline $\mathbf{2 0 0 7}$ & I8.26I & $8.27 \mathrm{I}$ & 9.990 & 45,3 & 54,7 \\
\hline $\mathbf{2 0 0 8}$ & I6.802 & 7.473 & 9.329 & 44,5 & 55,5 \\
\hline $\mathbf{2 0 0 9}$ & I6.236 & $7.45 \mathrm{I}$ & 8.785 & 45,9 & $54, \mathrm{I}$ \\
\hline
\end{tabular}

Fuente: Ministerio de Trabajo e Inmigración

Al observar estos datos destaca sobremanera el incremento producido en 2007 con respecto a 2006. Se produce un aumento del 9I,9\% en las afiliaciones de europeos de la Unión Europea. Se debe a la incorporación de Rumanía y Bulgaria a la UE, en el caso riojano especialmente a la incorporación del primero de los dos países. Con anterioridad ya era este país uno de los que contaba con mayor número de ciudadanos en España. En La Rioja, donde el colectivo rumano es especialmente significativo en términos relativos, el aumento fue muy superior, pues llegó hasta el I35,4 \%.

\section{V.2. Afiliación según régimen de cotización}

Los extranjeros afiliados en La Rioja cotizan en el Régimen General, en el Régimen Especial de Trabajadores Autónomos (RETA), en el Régimen Especial Agrario y en el Régimen de Empleados del Hogar. Los siguientes datos de cotización proporcionados por el Ministerio de Trabajo e Inmigración se refieren a 3I de diciembre de cada año señalado.

Afiliados totales por regímenes en España y en La Rioja

\begin{tabular}{|c|c|c|c|c|c|c|c|c|}
\hline \multirow[b]{2}{*}{ General } & \multicolumn{2}{|c|}{2006} & \multicolumn{2}{|c|}{2007} & \multicolumn{2}{|c|}{2008} & \multicolumn{2}{|c|}{2009} \\
\hline & I4.338.759 & $95.78 \mathrm{I}$ & I4.7I9.806 & 98.401 & 13.862.376 & 93.663 & I3.275.386 & 90.009 \\
\hline Autónomos & 3.052 .886 & 23.825 & 3.157 .930 & $24.95^{2}$ & 3.309 .590 & 28.084 & 3.157 .046 & 26.805 \\
\hline Agrario & I.001. 463 & $9 \cdot 3 \mathrm{II}$ & 974.027 & 8.703 & 775.940 & 5.049 & 849.076 & $5 \cdot 94 \mathrm{I}$ \\
\hline C. ajena & $747 \cdot 35 \mathrm{I}$ & 4.859 & 728.546 & 4.409 & --- & --- & --- & --- \\
\hline C. propia & $254 . \mathrm{II} 2$ & $4.45^{2}$ & $245 \cdot 48 \mathrm{I}$ & 4.294 & --- & --- & --- & --- \\
\hline E. hogar & 300.134 & І. 886 & 269.150 & I. $55^{\mathrm{I}}$ & 286.027 & I. 565 & 289.056 & I. 664 \\
\hline
\end{tabular}


Afiliados extranjeros por regímenes en España y en La Rioja

\begin{tabular}{|c|c|c|c|c|c|c|c|c|}
\hline \multirow[b]{2}{*}{ General } & \multicolumn{2}{|c|}{2006} & \multicolumn{2}{|c|}{2007} & \multicolumn{2}{|c|}{2008} & \multicolumn{2}{|c|}{2009} \\
\hline & I. 310.52 & I0.286 & I.440.977 & II.747 & I. 283.144 & 10.060 & I.I75.06I & 9.084 \\
\hline Autónomos & 164.630 & I.I46 & 223.597 & 2.127 & 221.609 & I.740 & I96.698 & I. 363 \\
\hline Agrario & I57.945 & $3 \cdot 52 \mathrm{I}$ & I59.372 & 3.333 & 202.622 & 3.929 & 260.423 & 4.629 \\
\hline C. ajena & I 57.252 & $3 \cdot 5^{\mathrm{II}}$ & I58.598 & $3 \cdot 320$ & --- & --- & --- & --- \\
\hline C. propia & 693 & IO & 774 & I3 & --- & --- & --- & --- \\
\hline E. hogar & I86.76I & I.379 & 152.803 & I.054 & I70.344 & I.073 & I75.276 & I.I60 \\
\hline
\end{tabular}

Porcentaje de afiliados extranjeros en España y La Rioja

ESPAÑA LA RIOJA

\begin{tabular}{l|cccc|cccc} 
& $\mathbf{2 0 0 6}$ & $\mathbf{2 0 0 7}$ & $\mathbf{2 0 0 8}$ & $\mathbf{2 0 0 9}$ & $\mathbf{2 0 0 6}$ & $\mathbf{2 0 0 7}$ & $\mathbf{2 0 0 8}$ & $\mathbf{2 0 0 9}$ \\
\hline TOTAL & 9,7 & I0,3 & I0,3 & I0,2 & I2,5 & I3,7 & I3,I & I3,0 \\
\hline General & $9, \mathrm{I}$ & 9,8 & 9,3 & 8,9 & I0,7 & II,9 & I0,7 & I0,I \\
\hline Autónomos & 5,4 & $7, \mathrm{I}$ & 6,7 & 6,2 & 4,8 & 8,5 & 6,2 & $5, \mathrm{I}$ \\
\hline Agrario & I5,8 & I6,4 & $26, \mathrm{I}$ & 30,7 & 37,8 & 38,3 & 77,8 & 77,9 \\
\hline C. ajena & $2 \mathrm{I}, 0$ & $2 \mathrm{I}, 8$ & --- & --- & 72,3 & 75,3 & -- & $\cdots$ \\
\hline C. propia & 0,3 & 0,3 & --- & --- & 0,2 & 0,3 & $\cdots$ & $\cdots$ \\
\hline E. hogar & 62,2 & 56,8 & 59,6 & 60,6 & $73, \mathrm{I}$ & 68,0 & 68,6 & 69,7 \\
\hline
\end{tabular}

Fuente: Ministerio de Trabajo e Inmigración

El análisis de las tablas ofrece información acerca de los sectores en los que la presencia extranjera es mayor. Destacan los datos referidos al Régimen Agrario y al de Empleadas del Hogar.

En La Rioja es especialmente significativo el dato sobre el Régimen Agrario por ser ésta una Comunidad Autónoma con una relevante producción agrícola. En este régimen el 77,8\% de los trabajadores era inmigrante en 2008 y sube ligeramente al 77,9\% en 2009 , siendo además trabajadores por cuenta ajena, pues hay una ausencia prácticamente total de propietarios de la tierra extranjeros.

En el Régimen de Empleadas del Hogar existe también un porcentaje muy elevado, pues en 2009 el 69,7\% de los trabajadores y trabajadoras de este sector en La Rioja era extranjero.

Sin embargo tanto los afiliados en el Régimen General como en el Régimen de los Trabajadores Autónomos (RETA) los porcentajes con respecto al total de trabajadores son muy inferiores. En el primer caso en 2009 en La Rioja era de un Io,1\% y en el del RETA de un 5,I\%, siguiendo ambos regímenes una tendencia decreciente desde 2007. Es necesario advertir que, como consecuencia de la aprobación de la Ley i8/2007 se ha producido un aumento en los cotizantes por el RETA al quedar incluidos en él los trabajadores de Régimen Especial Agrario. 
Los datos nos muestran que el inmigrante riojano trabaja por cuenta ajena, siendo algunos sectores como el de las empleadas del hogar y el de los trabajadores del campo un ámbito copado por los extranjeros. Por el contrario los extranjeros no se caracterizan por una presencia amplia entre los empresarios o comerciantes autónomos, pues su peso entre los cotizantes es muy bajo. Como conclusión se puede señalar que los inmigrantes responden a una notable demanda de mano de obra en la agricultura y en la atención doméstica.

\section{V.3. Afiliación por actividad (Régimen General)}

Si observamos los datos de 2008, en La Rioja destacan tres sectores, la construcción, las industrias manufactureras y la hostelería como ámbitos especialmente ocupados por trabajadores extranjeros. En el resto de España coinciden la construcción y la hostelería como dos de las actividades principales, sin embargo el comercio y reparación de vehículos se sitúan por encima de la construcción. En La Rioja el sector del comercio y reparación de vehículos no se incluye entre esas tres actividades principales, si bien también tiene un peso importante, no en vano alcanza un I0,7\%.

Afiliación de extranjeros en el Régimen General según la actividad

\begin{tabular}{|c|c|c|c|c|}
\hline ESPAÑA & 2006 & 2007 & 2008 & $\% 2008$ \\
\hline Total & $\mathrm{I} .310 .52 \mathrm{I}$ & I.440.977 & I.283.I43 & I00,0 \\
\hline Agricultura y ganad. & $\mathrm{I} 3.403$ & I5.087 & I5.733 & $\mathrm{I}, 2$ \\
\hline Pesca & I4I & I28 & $\mathrm{I} 45$ & 0,0 \\
\hline Ind. extractivas & 2.477 & 2.594 & 2.030 & 0,2 \\
\hline Ind. manufacturera & I36.837 & I57.697 & I3 $8.85 \mathrm{I}$ & Iо, 8 \\
\hline Energía & 936 & 1.026 & I.040 & O,I \\
\hline Construcción & $345 \cdot 984$ & 350.907 & 214.696 & 16,7 \\
\hline Comerc y reparac. vehic. & I98.iI6 & 219.837 & 219.872 & $\mathrm{I} 7, \mathrm{I}$ \\
\hline Hostelería & 215.048 & 240.026 & 243.627 & I9,0 \\
\hline Transportes & $64.29 \mathrm{I}$ & 78.055 & 73.769 & 5,7 \\
\hline Intermed. financ. & 6.518 & 7.760 & 8.034 & 0,6 \\
\hline Inmobiliaria & 203.535 & 222.695 & 204.027 & 15,9 \\
\hline Administración & I0.234 & I2.I44 & 13.693 & $\mathrm{I}, \mathrm{I}$ \\
\hline Educación & 24.965 & 28.057 & 30.846 & 2,4 \\
\hline Sanidad & 34.066 & $47 \cdot 7 \mathrm{I} 3$ & 56.531 & 4,4 \\
\hline Act. sociales & 5 I.3I9 & $53 \cdot 55^{\mathrm{I}}$ & 56.076 & 4,4 \\
\hline Hogares & 2.175 & 3.108 & $3.5 \mathrm{I} 6$ & 0,3 \\
\hline Org. extraterrit. & $47 \mathrm{I}$ & 592 & 657 & O,I \\
\hline Otros & 5 & ० & ० & 0,0 \\
\hline LA RIOJA & 2006 & 2007 & 2008 & $\% 2008$ \\
\hline Total & 10.286 & II.747 & 10.060 & IOO,O \\
\hline Agricultura y ganad. & 139 & I93 & I75 & $\mathrm{I}, 7$ \\
\hline
\end{tabular}




\begin{tabular}{lcccc} 
Pesca & II & 7 & 7 & O,I \\
\hline Ind. extractivas & I2 & I7 & I5 & 0,I \\
\hline Ind. manufacturera & 2.296 & 2.637 & 2.276 & 22,6 \\
\hline Energía & 6 & 6 & 8 & $0, \mathrm{I}$ \\
\hline Construcción & 3.475 & $3.7 \mathrm{II}$ & $2.3 \mathrm{I} 6$ & 23,0 \\
\hline Comerc y reparac. vehic. & 940 & I.070 & I.08I & I0,7 \\
\hline Hostelería & I.390 & I.599 & I.672 & 16,6 \\
\hline Transportes & 390 & 543 & 534 & 5,3 \\
\hline Intermed. financ. & 4 & 9 & 8 & $0, \mathrm{I}$ \\
\hline Inmobiliaria & 987 & I.098 & 962 & 9,6 \\
\hline Administración & 69 & 79 & 75 & 0,7 \\
\hline Educación & 58 & 69 & $7 \mathrm{I}$ & 0,7 \\
\hline Sanidad & 246 & 357 & $49 \mathrm{I}$ & 4,9 \\
\hline Act. sociales & 259 & 347 & 363 & 3,6 \\
\hline Hogares & 4 & 5 & 6 & $0, \mathrm{I}$ \\
\hline Org. extraterrit. & 0 & 0 & 0 & 0,0 \\
\hline Otros & 0 & 0 & 0 & 0,0 \\
\hline
\end{tabular}

Fuente: Ministerio de Trabajo e Inmigración

En 2008 tanto en España como en La Rioja se perdieron afiliados extranjeros al Régimen General. En España descendió en I57.834, o sea un II,O\%, mientras que en La Rioja fueron I.687 afiliados, un I4,4\%. Por tanto esta Comunidad Autónoma se vio más afectada que el resto del país en el descenso de afiliados.

Los sectores que en los que se produjo un mayor descenso coinciden con aquellos más afectados por la actual situación económica. Así, centrándonos en La Rioja, fueron la construcción, la industria manufacturera y las actividades inmobiliarias, sectores que disminuyeron en un $37,6 \%, \mathrm{I} 3,7 \%$ y $\mathrm{I} 2,4 \%$ respectivamente.

\section{Contratación}

En cuanto a la contratación en La Rioja entre los años 2005 y 2010 contamos con datos a 3I de diciembre. 
Contratos

ESPAÑA

LA RIOJA

\begin{tabular}{c|ccc|ccc} 
& Total & Extranjeros & $\%$ & Total & Extranjeros & $\%$ \\
\hline 2005 & I7.166.524 & 2.746 .364 & I6,0 & II2.54I & 31.343 & 27,9 \\
\hline 2006 & I8.526.772 & 3.555 .126 & I9,2 & I20.407 & 36.140 & 30,0 \\
\hline 2007 & I8.622.108 & 3.957 .393 & 21,3 & I20.567 & 40.777 & 33,8 \\
\hline 2008 & I6.601.237 & 3.631 .768 & 21,9 & II0.I28 & 39.222 & 35,6 \\
\hline 2009 & I4.021.837 & 2.947 .855 & 21,0 & 94.739 & 32.577 & 34,4 \\
\hline 2010 & I4.4I7.I50 & 2.912 .526 & 20,2 & I02.564 & 33.946 & 33, I \\
\hline
\end{tabular}

Fuente: Ministerio de Trabajo e Inmigración. Servicio Riojano de Empleo

La contratación de extranjeros tiene un peso mayor en La Rioja que en España y ha ido aumentando por lo menos hasta 2008. En 2005 un 27,9\% de las contrataciones riojanas fueron realizadas a extranjeros, mientras que en España era del i6,०\%. Ya en 2008 se alcanzó en La Rioja el 35,6\%, más de un tercio de las contrataciones, y en el total de España se quedó en un 2I,9\% porcentaje todavía muy alejado del nivel mínimo riojano de 2005. El período de crisis provocó que desde 2007 los niveles de contratación bajasen, sin embargo en 2008 tanto en España como en La Rioja se continuó contratando a extranjeros de forma creciente, si bien ya en 2009 se produjo una primera disminución de contratación extranjera. En 20Io los datos varían ligeramente. En La Rioja volvió a subir el nivel de contratación general y también el de extranjeros. En España, aunque las contrataciones subieron, no lo hicieron las de los trabajadores extranjeros.

Se observa que tanto en España como en La Rioja existe un incremento de la contratación absoluta en el trienio 2005-2007, experimentándose un descenso en 2008 debido a la nueva situación económica. En España el descenso de las contrataciones de extranjeros que se produjo en 2008 es del 8,2\%, sin embargo en La Rioja ese descenso no fue tan acusado, pues fue del $3,8 \%$.

Dentro de la contratación a extranjeros en 2008 un 32,3\% de los contratos lo fueron a trabajadores de la UE, siendo el resto, un $67,7 \%$, de fuera de ella. Se observa un importante salto en 2007 que de nuevo es debido a la incorporación de Rumania y Bulgaria a la Unión Europea.

\% de contratos a extranjeros en La Rioja según sean o no ciudadanos de la UE

\begin{tabular}{ccc} 
& UNIÓN EUROPEA & NO UNIÓN EUROPEA \\
\hline 2006 & I7,0 & 83,0 \\
\hline 2007 & 31,5 & 68,5 \\
\hline 2008 & 32,3 & 67,7 \\
\hline
\end{tabular}

Fuente: Ministerio de Trabajo e Inmigración. Servicio Riojano de Empleo

Por otra parte existe una clara masculinidad en la contratación. Según datos del Ministerio de Trabajo e Inmigración en España el 62,9\% de las contrataciones se realizaron a hombres, quedando el 37,I\% para las mujeres. En La Rioja la diferencia es mayor, pues el 
$70,9 \%$ se hicieron a hombres y tan solo el $29, \mathrm{I} \%$ a mujeres. Si ponemos estos porcentajes en relación con las tablas de cotizaciones observamos que en La Rioja la oferta de trabajo se ha centrado en puestos ocupados por varones, tales son la construcción, las industrias manufactureras y la agricultura. Sin embargo se puede observar que la diferencia ha ido disminuyendo. Los datos de La Rioja nos indican que en 2006 el 75,5\% de los contratos se hicieron a varones, en 2007 descendió al 71,5\% y en 2008 se quedó en un 70,9\%. Esto se ha debido a la mayor integración de las mujeres en el ámbito laboral con la llegada de un mayor número de ellas por el procedimiento de reagrupación familiar, las cuales se han ido incorporando al mercado laboral.

\section{VI.I. Tipos de contratación y sectores}

La característica principal y más importe de la contratación riojana a inmigrantes es su temporalidad. De los 39.222 contratos firmados con trabajadores extranjeros en 2008 , el 9I,4\% fueron temporales, siendo por tanto sólo el 8,6\% indefinidos. Este dato nos habla de la alta precariedad y movilidad del trabajo inmigrante.

\section{Contratación extranjera en La Rioja (2005-2008)}

\begin{tabular}{lcccc} 
& $\mathbf{2 0 0 5}$ & $\mathbf{2 0 0 6}$ & $\mathbf{2 0 0 7}$ & $\mathbf{2 0 0 8}$ \\
\hline TOTAL & II2.556 & I20.407 & I20.567 & II0.I28 \\
\hline Indefinidos & II.328 & I4.544 & I5.592 & I2.I87 \\
\hline Temporales & I0I.228 & I05.863 & I04.975 & 97.94I \\
\hline EXTRANJEROS & 31.343 & 36.140 & 40.777 & 39.222 \\
\hline Indefinidos & 2.347 & 3.414 & 3.918 & 3.365 \\
\hline Hombres & I.696 & 2.379 & 2.586 & 2.004 \\
\hline Mujeres & $65 \mathrm{I}$ & I.035 & I.332 & I.36I \\
\hline Temporales & 28.996 & 32.726 & 36.859 & 35.857 \\
\hline Hombres & 22.545 & 24.912 & 26.554 & 25.823 \\
\hline Mujeres & $6.45 \mathrm{I}$ & $7.8 \mathrm{I} 4$ & I0.305 & I0.034 \\
\hline \% extr. sobre total & 27,8 & 30,0 & 33,8 & 35,6 \\
\hline Indefinidos & 7,5 & 9,4 & 9,6 & 8,6 \\
\hline Temporales & 92,5 & 90,6 & 90,4 & 91,4 \\
\hline
\end{tabular}

Fuente: Servicio Riojano de Empleo

Contratación acumulada por sectores de actividad (2005-2008)

\begin{tabular}{lcccc} 
ESPAÑA & $\mathbf{2 0 0 5}$ & $\mathbf{2 0 0 6}$ & 2007 & $\mathbf{2 0 0 8}$ \\
\hline $\begin{array}{l}\text { CONTRATACIÓN } \\
\text { EXTRANJEROS }\end{array}$ & 2.746 .364 & 3.555 .126 & 3.957 .393 & 3.631 .768 \\
\hline Agricultura & 473.360 & 512.918 & 477.802 & 548.459 \\
\hline Industria & 159.175 & 192.926 & $217.41 \mathrm{II}$ & 183.343 \\
\hline Construcción & 620.924 & 832.590 & 901.209 & 678.320 \\
\hline Servicios & 1.492 .905 & 2.016 .692 & $2.360 .97 \mathrm{I}$ & 2.221 .646 \\
\hline
\end{tabular}




\begin{tabular}{|c|c|c|c|c|}
\hline HOMBRES & I. 838.622 & $2.338 .4 \mathrm{I} 4$ & 2.506 .129 & 2.286 .567 \\
\hline Agricultura & 366.229 & 384.073 & 338.848 & 395.483 \\
\hline Industria & II9. 523 & I 44.247 & I59.927 & $\mathrm{I} 35 \cdot 64 \mathrm{I}$ \\
\hline Construcción & 598.869 & 804.258 & 874.849 & 656.893 \\
\hline Servicios & 754.001 & I.005.836 & I.I32.505 & I. .998 .550 \\
\hline MUJERES & $907 \cdot 742$ & I.216.7I 2 & I. $45 \mathrm{I} .264$ & I. $345.20 \mathrm{I}$ \\
\hline Agricultura & I07.I3I & $\mathrm{I} 28.845$ & I38.954 & I52.976 \\
\hline Industria & 39.652 & 48.679 & 57.484 & 47.702 \\
\hline Construcción & 22.055 & 28.332 & 26360 & 21.427 \\
\hline Servicios & 738.904 & I.0I0.856 & I.228.466 & I.I23.096 \\
\hline \multicolumn{5}{|l|}{ \% EXTRANJEROS } \\
\hline HOMBRES & 66,9 & 65,8 & 63,3 & 63,0 \\
\hline Agricultura & 77,4 & 74,9 & 70,9 & $72, \mathrm{I}$ \\
\hline Industria & $75, \mathrm{I}$ & 74,8 & 73,6 & 74,0 \\
\hline Construcción & 96,4 & 96,6 & $97, \mathrm{I}$ & 96,8 \\
\hline Servicios & 50,5 & 49,9 & 48,0 & 49,4 \\
\hline LA RIOJA & 2005 & 2006 & 2007 & 2008 \\
\hline $\begin{array}{l}\text { CONTRATACIÓN } \\
\text { EXTRANJEROS } \\
\end{array}$ & 3 I. 343 & 36.140 & 40.777 & 39.222 \\
\hline Agricultura & 10.304 & 9.493 & 9.604 & I2.379 \\
\hline Industria & 3.582 & 4.089 & 4.737 & $4 \cdot 335$ \\
\hline Construcción & 6.693 & 8.971 & 9.458 & $7 \cdot 508$ \\
\hline Servicios & 10.764 & I3.587 & I6.978 & 15.000 \\
\hline HOMBRES & $24.24 \mathrm{I}$ & $27.29 \mathrm{I}$ & 29.140 & 27.827 \\
\hline Agricultura & 8.980 & 8.237 & 8.147 & I0.654 \\
\hline Industria & $2.72 \mathrm{I}$ & 3.056 & $3.2 \mathrm{I} 3$ & 2.876 \\
\hline Construcción & 6.585 & $8.8 \mathrm{I} 7$ & $9 \cdot 326$ & 7.406 \\
\hline Servicios & 5.955 & $7 . \mathrm{I} 8 \mathrm{I}$ & 8.454 & $6.89 \mathrm{I}$ \\
\hline MUJERES & 7.102 & 8.849 & II. 637 & II. 395 \\
\hline Agricultura & I. 324 & 1.256 & I. 457 & I. 725 \\
\hline Industria & $86 \mathrm{I}$ & I.O33 & I. 524 & I.459 \\
\hline Construcción & I08 & I54 & $\mathrm{I} 32$ & IO2 \\
\hline Servicios & 4.809 & 6.406 & 8.524 & 8.109 \\
\hline \multicolumn{5}{|l|}{ \% EXTRANJEROS } \\
\hline HOMBRES & 77,3 & 75,5 & $7 \mathrm{I}, 5$ & 70,9 \\
\hline Agricultura & 87,2 & 86,8 & 84,8 & $86, \mathrm{I}$ \\
\hline Industria & 76,0 & 74,7 & 67,8 & 66,3 \\
\hline Construcción & 98,4 & 98,3 & 98,6 & 98,6 \\
\hline Servicios & 55,3 & 52,9 & 49,8 & 45,9 \\
\hline
\end{tabular}

Fuente: Servicio Riojano de Empleo 
En La Rioja, durante 2008 fue el sector servicios el que tuvo un mayor nivel de contratación $-38,2 \%-$, siguiendo una línea que venía repitiéndose en los años anteriores, si bien ese año hay un ligero descenso tanto a nivel total como porcentual con respecto a 2007. El dato tiene especial relevancia si lo ponemos en relación con el porcentaje español, que alcanza un extraordinario 6r,2\% y que nos habla del gran peso que los servicios tienen en la contratación extranjera debido al abandono de estos puestos de trabajo por el trabajador nacional.

En paralelo en La Rioja se produce en 2008 un aumento considerable de la contratación agrícola y una disminución de la contratación en el sector de la construcción, sin duda debido a su ralentización como motor económico del país. Se observa que la disminución de los sectores señalados también se ha producido en el resto del país, y de igual manera la agricultura ha aumentado. Se debe al trasvase de trabajadores desde sectores más afectados por la situación económica -construcción, industria, servicios- hacia el trabajo en el campo.

Teniendo en cuenta el sexo, se observa en 2008 que todos los sectores excepto los servicios, están en La Rioja dominados por los hombres. Especialmente significativos son el sector agrícola, donde el 86,1\% es trabajador masculino, y sobre todo la construcción, con un $98,6 \%$ de hombres. En los servicios hay una práctica equiparación de hombres y mujeres, si bien éstas tienen a su favor un pequeña diferencia -54,I\%-. Estos datos son similares a los ofrecidos para el resto de España.

VI.2. Contratación por procedencia geográfica

Contratos a extranjeros según procedencia geográfica en España y La Rioja

\begin{tabular}{|c|c|c|c|c|c|c|}
\hline \multirow[b]{2}{*}{ Total } & \multicolumn{2}{|c|}{2006} & \multicolumn{2}{|c|}{2007} & \multicolumn{2}{|c|}{2008} \\
\hline & 3.555 .126 & 36.140 & 3.957 .393 & 40.777 & 3.631 .7683 & 9.222 \\
\hline Unión Europea & 867.521 & 10.426 & I. 043.548 & I2.855 & $995 \cdot 312$ & I2.686 \\
\hline Resto de Europa & I07.993 & $68 \mathrm{I}$ & II 4.315 & $55^{\mathrm{I}}$ & 105.319 & 561 \\
\hline África & $\mathrm{I} .025 .434$ & Іт. 688 & I.091.602 & 13.098 & 953.465 & I2.777 \\
\hline América del Norte & 6.I55 & 4 & 6.201 & 9 & 5.723 & 7 \\
\hline Asia & I79.398 & 4.159 & I88.983 & 3.834 & I84.457 & 3.613 \\
\hline Latinoamérica & I.360.100 & $9 . \mathrm{I} 2 \mathrm{I}$ & I. 505.388 & 10.369 & I. 382.073 & $9 \cdot 547$ \\
\hline Oceanía & 2.926 & 32 & 2.921 & 37 & $2.3 \mathrm{IO}$ & I8 \\
\hline No consta & 5.599 & 29 & 4.435 & 24 & 3.109 & I3 \\
\hline
\end{tabular}

Fuente: Servicio Riojano de Empleo

Si se tiene en cuenta la procedencia geográfica de los trabajadores, en 2008 el mayor número de contratos en La Rioja se hicieron con africanos debido al gran peso de la inmigración marroquí en nuestra región. Fueron el 32,6\% de los mismos, si bien la contratación con europeos comunitarios se aproximó bastante, pues porcentualmente llegó al 32,3\%, donde los rumanos tienen una especial incidencia. La progresiva equiparación que se ha dado en los tres años señalados se debe de nuevo por tanto a la incorporación de los rumanos a la Unión Europea. En 2006, año anterior a este hecho, la diferencia en el número de contratos entre africanos y ciudadanos de la U.E. fue de 1.262 a favor de los primeros. Sin embargo en 2008 la diferencia sólo fue de 9I contratos. 
Es necesario destacar también que en La Rioja el peso de la contratación latinoamericana es menor que en el resto de España. En nuestro país la mayor parte de los contratos que se hicieron entre 2006 y 2008 lo fueron con extranjeros procedentes de Latinoamérica. En La Rioja no sólo no es el colectivo con más contratación, sino que desciende al tercer lugar por detrás de los ciudadanos de la U.E. -rumanos- y los africanos -marroquíes-. Estos, en 2008 y en el ámbito español, fueron precisamente el tercer colectivo geográfico en cuanto a contratación.

Contratación de extranjeros por sectores y procedencia geográfica en La Rioja (2008)

\begin{tabular}{lccccccccc} 
& Total & Agric. & Indus. & Constr. & Serv. & Agric. & Indus. & Constr. & Serv. \\
\hline La Rioja & 39.222 & I2.379 & 4.335 & 7.508 & I5.000 & $3 \mathrm{I}, 6$ & II,I & I9,I & 38,2 \\
\hline Unión Europea & I2.686 & 5.022 & I.I34 & 2.562 & 3.968 & 39,6 & 8,9 & 20,2 & $3 \mathrm{I}, 3$ \\
\hline Resto Europa & $56 \mathrm{I}$ & 37 & I42 & I33 & 249 & 6,6 & 25,3 & 23,7 & 44,4 \\
\hline África & I2.777 & $6 . \mathrm{I} 29$ & I.2I4 & I.760 & 3.674 & 48,0 & 9,5 & I3,8 & 28,8 \\
\hline América del Norte & 7 & $\circ$ & $\circ$ & I & 6 & 0,0 & 0,0 & I4,3 & 85,7 \\
\hline Asia & $3.6 \mathrm{I} 3$ & 636 & 492 & I.39I & I.094 & I7,6 & I3,6 & 38,5 & 30,3 \\
\hline Latinoamérica & 9.547 & 544 & I.350 & I.652 & $6.00 \mathrm{I}$ & 5,7 & I4,I & I7,3 & 62,9 \\
\hline Oceanía & I8 & 6 & 3 & 6 & 3 & 33,3 & I6,7 & 33,3 & I6,7 \\
\hline No consta & I3 & 5 & 0 & 3 & 5 & 38,5 & 0,0 & $23, \mathrm{I}$ & 38,5 \\
\hline
\end{tabular}

Fuente: Servicio Riojano de Empleo

El grupo geográfico más numeroso en La Rioja es el de extranjeros procedentes de África, donde hemos señalado que destacan los de origen marroquí, con I2.777 contratos según datos de 2008. Muy cerca se encuentra el de los ciudadanos de la Unión Europea. Ya se ha señalado la relevancia del colectivo rumano dentro de este grupo. En tercer lugar destacan también los latinoamericanos con 9.547. Estos tres grupos suman la gran mayoría de los contratos, llegando al $86,26 \%$ de los mismos. Muy por detrás están colectivos como los asiáticos y los residentes en el resto de Europa, siendo mínima la representación de extranjeros procedentes de Oceanía y América del Norte.

En La Rioja el $38,24 \%$ de los contratos a extranjeros se hicieron para el sector servicios y el 3I,52\% en agricultura. Son los dos grandes sectores de contratación en 2008 , si bien la construcción también tiene ese año un papel relevante con un 19,I4\% de contratación. Es reflejo del peso de estos tres sectores en la economía riojana en 2008.

Los datos ofrecidos por la anterior tabla nos hablan de una especialización de acuerdo con la procedencia geográfica de los trabajadores. Así, centrándonos únicamente en los colectivos con mayor presencia en La Rioja, tales son los rumanos, los marroquíes y los latinoamericanos, se puede señalar que los ciudadanos de la Unión Europea, si bien trabajan mayoritariamente en la agricultura -un 39,6\%-, también ocupan en buen número de puestos en el sector servicios, pues llegan al 3I,3\% de los contratos. Sin embargo entre los africanos la diferencia es mucho más significativa. Casi la mitad de los contratos son en este caso agrícolas -el 48,०\%-, si bien tiene bastante relevancia el sector servicios, con un $28,8 \%$ de la contratación. Es entre los latinoamericanos donde se produce una verdadera polarización, pues el $62,9 \%$ de los contratos de este colectivo están destinados a los servicios, siendo la construcción el siguiente sector de contratación con un 17,3\%. Se aprecia por tanto una gran especialización y nos habla de una masculinización de los 
trabajadores latinoamericanos pues, como vimos, prácticamente la totalidad de los contratos en este sector se realizan a hombres.

Los asiáticos también son un grupo relevante si bien, como se puede apreciar en la tabla sobre contratos a extranjeros por procedencia geográfica, es el cuarto colectivo a cierta distancia del latinoamericano, yendo además su trayectoria en descenso desde 2006. En este grupo es significativo el dato, pues es la construcción donde más contratación hay I.39I contratos y un 38,5\%-, si bien se encuentra muy cerca de los servicios -I.094 contratos y un $30,3 \%-$.

\section{Parados extranjeros en La Rioja}

La crisis económica general ha afectado de forma especial al empleo. En países como España, con un paro estructural muy elevado, ha repercutido especialmente, alcanzándose niveles que no se habían dado desde hacía dos décadas. En este apartado se va a incidir en el trienio 2006-2008 en el cual se pasó de una situación de reducción de paro a un aumento del mismo tras la crisis económica desatada en el año 2007. Desde entonces los niveles de paro han aumentado considerablemente.

En España hay un gran salto en el número de parados registrados a 3I de diciembre entre los años 2007 y 2008, años clave en el período de crisis. En concreto son I.oI6.4I6 más los registrados en este segundo año, lo que supone un aumento del 48,I\%. En La Rioja aún se produjo un incremento mayor, pues los 5.9I 8 parados más en 2008 hablan de un $55,0 \%$ de incremento.

Bajando al colectivo extranjero los datos son muy significativos pues una cuarta parte de los parados riojanos de ese año -el 25,8\%- pertenecen a este colectivo. Los sectores especialmente afectados son el agrícola y la construcción. En el primero más de la mitad de los parados riojanos -52,I\%- eran inmigrantes; en el segundo, la construcción, el porcentaje no es tal alto pero se aproxima también al cincuenta por ciento -46,9\%-. Ambos destacan sobre la industria y los servicios $-20,1 \%$ y I7,8\% respectivamente-, sectores con un menor peso económico. Ya en 2007 se aprecia que la tendencia constante o levemente decreciente del paro entre los extranjeros riojanos, se rompe. En ese año hay un aumento considerable del paro registrado, llegándose al 39,2\%, tendencia que no sólo se confirma, sino que se agrava al año siguiente al producirse un incremento extraordinario del $104,2 \%$. Se puede concluir que en La Rioja el parado de 2008 se trata de un varón, marroquí, que tiene entre 30 y 34 años, y que es trabajador en el sector de la construcción realizando trabajos no cualificados ${ }^{\mathrm{II}}$.

Evolución del paro registrado por sector de actividad entre 2005 y 2008. A 3I de diciembre

\begin{tabular}{lcccc} 
ESPAÑA & 2005 & 2006 & 2007 & 2008 \\
\hline PARO TOTAL & 2.102 .937 & 2.022 .873 & 2.112 .547 & 3.128 .963 \\
\hline Agricultura & 65.227 & 61.494 & $68.8 \mathrm{I} 2$ & 101.338 \\
\hline Industria & 301.319 & 282.148 & $279.98 \mathrm{I}$ & 399.872 \\
\hline Construcción & 245.100 & $236.77 \mathrm{I}$ & 286.867 & 590.730 \\
\hline Servicios & I.266.389 & I.224.869 & 1.264.250 & I.776.050 \\
\hline
\end{tabular}

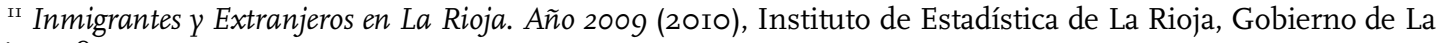
Rioja, p. 83.
} 


\begin{tabular}{|c|c|c|c|c|}
\hline Sin empleo anterior & 224.902 & $2 \mathrm{I} 7.59 \mathrm{I}$ & 212.637 & 260.973 \\
\hline EXTRANJEROS & I53.480 & I70.I50 & 2II.965 & 410.960 \\
\hline Agricultura & $9 \cdot 382$ & 7.109 & $9 \cdot 389$ & I8.885 \\
\hline Industria & II.I53 & I2.339 & $\mathrm{I} 4.803$ & 32.080 \\
\hline Construcción & 25.990 & $34.56 \mathrm{I}$ & 53.056 & I 24.875 \\
\hline Servicios & 85.204 & 96.740 & II 5.592 & I99.2I5 \\
\hline Sin empleo anterior & $2 \mathrm{I} .75^{\mathrm{I}}$ & I9.4OI & I9.I25 & 35.905 \\
\hline \% EXTRANJEROS & 7,3 & 8,4 & IO,O & I3,I \\
\hline Agricultura & $\mathrm{I} 4,4$ & II, 6 & 13,6 & I8,6 \\
\hline Industria & 3,7 & 4,4 & 5,3 & 8,0 \\
\hline Construcción & I0,6 & I4,6 & 18,5 & $2 \mathrm{I}, \mathrm{I}$ \\
\hline Servicios & 6,7 & 7,9 & $9, \mathrm{I}$ & $\mathrm{II}, 2$ \\
\hline Sin empleo anterior & 9,7 & 8,9 & 9,0 & $\mathrm{I} 3,8$ \\
\hline LA RIOJA & 2005 & 2006 & 2007 & 2008 \\
\hline PARO TOTAL & 10.279 & IO.I54 & I0.753 & I6.67I \\
\hline Agricultura & $38 \mathrm{I}$ & 266 & 325 & 753 \\
\hline Industria & 2.769 & 2.840 & 2.657 & 4.000 \\
\hline Construcción & I.027 & I.097 & I. 443 & $3.17 \mathrm{I}$ \\
\hline Servicios & $5 \cdot 55^{\mathrm{I}}$ & $5 \cdot 4 \mathrm{I} 7$ & $5 \cdot 766$ & 8.206 \\
\hline Sin empleo anterior & $55^{\mathrm{I}}$ & 534 & 562 & $54 \mathrm{I}$ \\
\hline EXTRANJEROS & I. 579 & I.5IO & 2.102 & 4.293 \\
\hline Agricultura & $\mathrm{I} 77$ & 99 & 126 & 392 \\
\hline Industria & 318 & 293 & 403 & 805 \\
\hline Construcción & $34 \mathrm{I}$ & $4 \mathrm{IO}$ & 653 & I. 486 \\
\hline Servicios & 630 & 608 & $8 \mathrm{I} 2$ & 1.462 \\
\hline Sin empleo anterior & II3 & 100 & I08 & $\mathrm{I} 48$ \\
\hline \% EXTRANJEROS & I5,4 & I4,9 & I9,5 & 25,8 \\
\hline Agricultura & 46,5 & 37,2 & 38,8 & $52, \mathrm{I}$ \\
\hline Industria & $\mathrm{II}, 5$ & 10,3 & $\mathrm{I}_{5}, 2$ & $20, \mathrm{I}$ \\
\hline Construcción & 33,2 & 37,4 & 45,3 & 46,9 \\
\hline Servicios & $\mathrm{II}, 3$ & $\mathrm{II}, 2$ & $\mathrm{I} 4, \mathrm{I}$ & $\mathrm{I} 7,8$ \\
\hline Sin empleo anterior & 20,5 & I 8,7 & 19,2 & 27,4 \\
\hline
\end{tabular}

Fuente: Servicio Riojano de Empleo

El paro en España en 2008 es mayor en el sector de los servicios, cuyo porcentaje sube al $48,5 \%$, quedándose el de los extranjeros de La Rioja correspondientes a este mismo sector en un 34,I\%. Sin embargo los trabajadores extranjeros, en el global español, superan ligeramente a los riojanos en otro de los sectores clave, la construcción. Aquí los primeros alcanzan el 34,6\%, si bien los segundos se acercan con un 30,4\%. 
El paro riojano de los extranjeros en la agricultura ha acumulado un espectacular 2II\%, muy superior no sólo al porcentaje español -IOI,I\%-, sino también al otro sector especialmente castigado, la construcción, con un 127,6\%, que sin embargo en España supera el nivel riojano, pues llega al $\mathrm{I} 35,4 \%$. Esto redunda en el significativo peso de la agricultura en nuestra región.

\section{Paro registrado por sector}

\begin{tabular}{|c|c|c|c|c|}
\hline ESPAÑA & 2006 & 2007 & 2008 & $\% 2008$ \\
\hline TOTAL & I70.I45 & 2II.966 & 410.960 & IOO \\
\hline Sin actividad & I9.399 & I9.126 & $35 \cdot 905$ & 8,7 \\
\hline Agricultura y ganadería & 6.716 & 8.904 & I8.3I2 & 4,5 \\
\hline Pesca & 393 & 485 & 573 & O,I \\
\hline Ind. extractivas & 788 & 630 & I.I25 & 0,3 \\
\hline Ind. manufactureras & II. 375 & I3.913 & 30.449 & 7,4 \\
\hline Prod. energía & I75 & 260 & 506 & $0, \mathrm{I}$ \\
\hline Construcción & $34.56 \mathrm{I}$ & 53.055 & I24.875 & 30,4 \\
\hline Coer. rep. vehículos & I2. 835 & I5.923 & 28.704 & 7,0 \\
\hline Hostelería & 29.134 & 33.360 & 52.266 & $\mathrm{I} 2,7$ \\
\hline Transportes & 3.272 & 4.III & $9 \cdot 334$ & 2,3 \\
\hline Interm. financieros & 390 & 575 & 719 & 0,2 \\
\hline Act. inmobiliaria & 37.093 & 46.706 & 83.894 & 20,4 \\
\hline Admón. Pública & I. 987 & 2.312 & 3.470 & 0,8 \\
\hline Educación & I. 570 & I. 675 & 2.485 & 0,6 \\
\hline Activ. sanitarias & 2.102 & $2.4 \mathrm{II}$ & 4.201 & $\mathrm{I}, \mathrm{O}$ \\
\hline Otras act. sociales & $5 \cdot 919$ & $6.36 \mathrm{I}$ & 10.592 & 2,6 \\
\hline Hogares & $2.4 \mathrm{I} 6$ & 2.136 & 3.520 & 0,9 \\
\hline Org. Territorial & 20 & 23 & 30 & 0,0 \\
\hline LA RIOJA & 2006 & 2007 & 2008 & $\% 2008$ \\
\hline TOTAL & I. 5 IO & 2.102 & 4.293 & IOO \\
\hline Sin actividad & IOO & I08 & 148 & 3,4 \\
\hline Agricultura y ganadería & 99 & I26 & 390 & $9, \mathrm{I}$ \\
\hline Pesca & $\circ$ & ० & 2 & 0,0 \\
\hline Ind. extractivas & 3 & ० & I & 0,0 \\
\hline Ind. manufactureras & 288 & 403 & 793 & $\mathrm{I} 8,5$ \\
\hline Prod. energía & 2 & ० & II & 0,3 \\
\hline Construcción & 410 & 653 & I.486 & 34,6 \\
\hline Coer. rep. vehículos & 73 & 92 & 176 & $4, \mathrm{I}$ \\
\hline Hostelería & I44 & $\mathrm{I} 74$ & 29I & 6,8 \\
\hline Transportes & 24 & $3 \mathrm{I}$ & 94 & 2,2 \\
\hline
\end{tabular}




\begin{tabular}{lcccc} 
Interm. financieros & I & O & I & 0,0 \\
\hline Act. inmobiliaria & 273 & 395 & 720 & I6,8 \\
\hline Admón. Pública & I7 & I6 & 22 & 0,5 \\
\hline Educación & 2 & I4 & I7 & 0,4 \\
\hline Activ. sanitarias & I8 & 26 & 47 & I,I \\
\hline Otras act. sociales & 26 & 44 & 74 & I,7 \\
\hline Hogares & 30 & 20 & 20 & 0,5 \\
\hline Org. Territorial & $\circ$ & 0 & 0 & 0,0 \\
\hline
\end{tabular}

Fuente: Servicio Riojano de Empleo

En prácticamente todos los sectores más importantes de la economía riojana se ha visto incrementado el paro durante los tres años contemplados. De forma especial en el sector de la construcción. Quizás solo habría que mencionar a los trabajadores del hogar, que en 2006 fueron 30 parados y en 2007 y 2008 bajaron a 20.

Analizando los datos de 2008 , en números totales y en La Rioja son la construcción, con I.486 parados; las industrias manufactureras, con 793; las actividades inmobiliarias, con 720; la agricultura y ganadería, con 390 y la hostelería, con 29I; las actividades más afectadas. Con respecto a España sólo el sector de los «sin actividad» tiene números más elevados, correspondiéndose en líneas generales los sectores más afectados tanto en el ámbito español como riojano. En España también es la construcción el que más destaca -I24.875-, si bien es el de las actividades inmobiliarias -83.894- el que le sigue en importancia, cuando vimos que en La Rioja es superado por las industrias manufactureras. En definitiva, tanto en España como en La Rioja vuelven a ser los trabajos relacionados con la actividad constructiva, entre los que incluiríamos las actividades inmobiliarias, los más afectados por la crisis económica. Sumando ambos llegan a porcentajes que rondan el cincuenta por ciento, en concreto en España para el año 2008 sumaron el 50,8\%, y en La Rioja el 5I,4\%.

Paro registrado de extranjeros según continentes de origen

\begin{tabular}{|c|c|c|c|c|}
\hline ESPAÑA & 2006 & 2007 & 2008 & \% VAR. 2008 \\
\hline TOTAL & I70.I45 & 211.966 & 410.960 & 93,9 \\
\hline Unión Europea & 44.622 & 58.659 & II9.897 & IO4,4 \\
\hline Resto de Europa & 6.I5I & $7 \cdot 701$ & I4.532 & 88,7 \\
\hline África & $49 \cdot 953$ & $63.88 \mathrm{I}$ & I2I.280 & 89,9 \\
\hline Latinoamérica & $64.22 \mathrm{I}$ & 75.474 & I42.645 & 89,0 \\
\hline América del Norte & 457 & 426 & 628 & 47,4 \\
\hline Asia & 4.285 & $5 \cdot 43 \mathrm{I}$ & II.4IO & IIO,I \\
\hline Oceanía & 138 & I68 & 286 & 70,2 \\
\hline No consta & 3I 8 & 226 & 282 & 24,8 \\
\hline \multicolumn{5}{|l|}{ PORCENTAJES } \\
\hline Unión Europea & 26,2 & 27,2 & 29,2 & $\mathrm{I}, 5$ \\
\hline Resto de Europa & 3,6 & 3,6 & 3,5 & $-\mathrm{O}, \mathrm{I}$ \\
\hline
\end{tabular}




\begin{tabular}{lcccc} 
África & 29,4 & $30, \mathrm{I}$ & 29,5 & $-0,6$ \\
\hline Latinoamérica & 37,7 & 35,6 & 34,7 & $-0,9$ \\
\hline América del Norte & 0,3 & 0,2 & 0,2 & 0,0 \\
\hline Asia & 2,5 & 2,6 & 2,8 & 0,2 \\
\hline Oceanía & $0, \mathrm{I}$ & $0, \mathrm{I}$ & $0, \mathrm{I}$ & 0,0 \\
\hline No consta & 0,2 & $0, \mathrm{I}$ & $0, \mathrm{I}$ & 0,0 \\
\hline
\end{tabular}

LA RIOJA

\begin{tabular}{|c|c|c|c|c|}
\hline TOTAL & I. $5 \mathrm{IO}$ & 2.102 & 4.293 & 104,2 \\
\hline Unión Europea & 275 & 487 & I.I76 & $\mathrm{I} 4 \mathrm{I}, 5$ \\
\hline Resto de Europa & 30 & 42 & 73 & 73,8 \\
\hline África & $55^{2}$ & 788 & I.427 & $8 \mathrm{I}, \mathrm{I}$ \\
\hline Latinoamérica & 473 & 570 & I.I34 & 98,9 \\
\hline América del Norte & o & I & 5 & 400,0 \\
\hline Asia & I75 & $2 \mathrm{II}$ & 474 & $\mathrm{I} 24,6$ \\
\hline Oceanía & 3 & 2 & 3 & 50,0 \\
\hline No consta & 2 & I & I & 0,0 \\
\hline \multicolumn{5}{|l|}{ PORCENTAJES } \\
\hline Unión Europea & $\mathrm{I} 8,2$ & 23,2 & 27,4 & 4,2 \\
\hline Resto de Europa & 2,0 & 2,0 & $\mathrm{I}, 7$ & $-0,3$ \\
\hline África & 36,6 & 37,5 & 33,2 & $-4,2$ \\
\hline Latinoamérica & $3 \mathrm{I}, 3$ & $27, \mathrm{I}$ & 26,4 & $-0,7$ \\
\hline América del Norte & 0,0 & 0,0 & O,I & O,I \\
\hline Asia & II, 6 & IO,O & II,O & $\mathrm{I}, \mathrm{O}$ \\
\hline Oceanía & 0,2 & O,I & $\mathrm{O}, \mathrm{I}$ & 0,0 \\
\hline No consta & $\mathrm{O}, \mathrm{I}$ & 0,0 & 0,0 & 0,0 \\
\hline
\end{tabular}

Fuente: Servicio Riojano de Empleo

En La Rioja, ciñéndonos a 2008, el grupo más numeroso de parados por continente de origen es el de los africanos, en los que se incluye el importante colectivo magrebí, con I.427 integrantes, los cuales se corresponden con el 33,2\% de parados extranjeros riojanos. Sin embargo hay un ligero descenso del peso del paro africano si tenemos en cuenta los datos de 2006 y 2007.

También los extranjeros procedentes de Latinoamérica, colectivo muy significativo, han experimentado un incremento claro, pasando de 473 en 2006 a I.I34 en 2008. Sin embargo en cuanto al porcentaje dentro del total de parados extranjeros ha descendido, quedando en el año 2008 en un $26,4 \%$, cuando en 2006 alcanzaban el 3I,3\% y en 2007 el 27,I\%. Se debe sin duda a que otros grupos han subido de forma considerable, es el caso del colectivo de europeos de la Unión Europea, rumanos en especial, cuyo paro ha ido aumentando su peso en estos tres años, pasando de un 18,2\% en 2006 a un $27,4 \%$ en 2008. El número de parados europeos comunitarios en La Rioja ha subido desde 275 en 2006, a un espectacular número de I.I76 en el año 2008. De nuevo tiene una explicación vinculada a la incorporación de Rumania y Bulgaria la Unión Europea en 2007. Sin 
embargo el número de parados comunitarios es muy escaso y poco significativo. En La Rioja había únicamente 73 parados en 2008 , lo que implica un I,7\% del total de los parados extranjeros riojanos.

Bajando a los datos sobre países, de acuerdo con los datos ofrecidos por el Servicio Riojano de Empleo, a 3I de diciembre de 2008, los porcentajes eran los siguientes:

\begin{tabular}{l|l|l|l} 
Marruecos & $23,0 \%$ & Portugal & $7,7 \%$ \\
\hline Rumanía & I5,4\% & Bolivia & $3,4 \%$ \\
\hline Colombia & $8,7 \%$ & Argelia & $3,3 \%$ \\
\hline Pakistán & $8,7 \%$ & Resto & $2 \mathrm{I}, 2 \%$ \\
\hline Ecuador & $8,6 \%$ & & \\
\hline
\end{tabular}

Fuente: Servicio Riojano de Empleo

Como ya se ha indicado, el alto porcentaje de rumanos parados explica también el considerable aumento de parados comunitarios.

Paro de extranjeros según su nivel de formación

\begin{tabular}{lcccc} 
ESPANA & $\mathbf{2 0 0 6}$ & $\mathbf{2 0 0 7}$ & $\mathbf{2 0 0 8}$ & \% VAR. 2008 \\
\hline TOTAL & I70.I45 & 2II.966 & 4 I0.960 & I00,0 \\
\hline Est. Primarios incompl. & 40.667 & 54.913 & I08.892 & 26,5 \\
\hline Est. Primarios compl. & I8.60I & 26.984 & 56.750 & I3,8 \\
\hline Formación profesional & 2.462 & 3.329 & 6.289 & I,5 \\
\hline Est. Secundarios & 96.214 & III.343 & 208.179 & 50,7 \\
\hline Est. Técnicos & I.227 & I.286 & 2.376 & 0,6 \\
\hline Est. Primer ciclo & I.315 & I.427 & 2.239 & 0,5 \\
\hline $\begin{array}{l}\text { Est. Segundo y Tercer } \\
\text { ciclo }\end{array}$ & 3.016 & 3.043 & 5.138 & I,3 \\
\hline Analfabetos & 97 & I20 & I79 & 0,0 \\
\hline Indeterminado & 6.546 & $9.52 \mathrm{I}$ & $20.9 \mathrm{I} 8$ & $5, \mathrm{I}$ \\
\hline
\end{tabular}

\section{LA RIOJA}

\begin{tabular}{lcccc}
\hline TOTAL & I.5IO & 2.IO2 & 4.293 & I00,0 \\
\hline Est. Primarios incompl. & 432 & 588 & 2.282 & 53,2 \\
\hline Est. Primarios compl. & 86 & 266 & 278 & 6,5 \\
\hline Formación profesional & 6 & I6 & $3 \mathrm{I}$ & 0,7 \\
\hline Est. Secundarios grales. & 900 & I.I 86 & I.636 & $38, \mathrm{I}$ \\
\hline Est. Técnicos & 7 & 8 & 3 & $0, \mathrm{I}$ \\
\hline Est. Primer ciclo & 0 & II & I3 & 0,3 \\
\hline $\begin{array}{l}\text { Est. Segundo y Tercer } \\
\text { ciclo }\end{array}$ & 5 & IO & I6 & 0,4 \\
\hline Analfabetos & 54 & I6 & 33 & 0,8 \\
\hline Indeterminado & 20 & I & I & 0,0 \\
\hline
\end{tabular}

Fuente: Servicio Riojano de Empleo 
Por otro lado en el caso riojano los extranjeros menos formados son los que han sufrido de forma más clara el período de crisis global en el que nos encontramos. En 2008 más de la mitad de los parados extranjeros $-53,2 \%$ - no tenían estudios primarios completos. El dato varía considerablemente con respecto a España. Teniendo en cuenta todo el país es el colectivo de los extranjeros con estudios secundarios generales el que más ha sufrido la situación de paro, pues fueron 208.179 y un 50,7\% del total de parados. También a nivel nacional tuvieron en 2008 un peso fundamental los extranjeros sin formación primaria, pues alcanzó un nada despreciable $26,5 \%$ y una cifra de io 8.892 parados.

Hay que destacar el bajo nivel de paro de los trabajadores con formación superior, pero especialmente hay que mencionar el bajo nivel de paro de los extranjeros poseedores de formación profesional. En La Rioja fueron 3I los parados en 2008, con un porcentaje del $0,7 \%$. Pero es que en toda España se repitió la misma situación, pues fueron 6.289 parados que alcanzaron un exiguo porcentaje del $\mathrm{I}, 5 \%$. La cualificación profesional es un factor fundamental para conseguir trabajo, y que son los menos cualificados los que primero engrosan las estadísticas de paro y más dificultades tienen de volver a encontrar un trabajo.

\section{Conclusiones}

La Rioja es una de las comunidades autónomas con mayor porcentaje de población extranjera apreciándose un mantenimiento de los altos niveles en el año 20Io, cuando se llegó a un i4,48\% de la población total. A pesar de que la llegada de inmigrantes durante los últimos años ha estado ligada a un aumento de la oferta de trabajo del mercado laboral, la actual situación de crisis económica global no ha provocado hasta 2010 una gran disminución del número de autorizaciones de residencia, aunque sí es previsible en los próximos años. En el resto de España se ha producido una ralentización en el número de autorizaciones concedidas por lo que los datos riojanos inciden en las diferencias existentes entre la inmigración laboral española y riojana. Tanto en La Rioja como en España se observa un aumento porcentual de extranjeros con residencia permanente o de larga duración, si bien no ocurre lo mismo con los datos sobre de comunitarios. En La Rioja fue mayor el incremento porcentual de autorizaciones para este grupo entre 2007 y 2010 y se ha debido al importante peso de la inmigración rumana.

La actividad laboral mayoritaria desarrollada por los trabajadores extranjeros en La Rioja en los mismos tres años ha sido la construcción, coincidiendo con el resto del país. Aún así en nuestra región los porcentajes de incidencia son mayores a la media española y difieren en relación con el resto de actividades mayoritarias. Por ejemplo en La Rioja el trabajador extranjero ha ocupado también en buena medida puestos de trabajo en la industria, en los servicios del hogar y en la hostelería, destacando especialmente el sector agrícola. En el resto de España el trabajador extranjero se ha centrado en el sector de la construcción, pero seguidamente en los servicios domésticos y turísticos, y en un grado menor en la industria y agricultura, lo que nos habla de que las ocupaciones de los trabajadores extranjeros se ajustan a la estructura económica de La Rioja, distinta de la del resto de España.

Esa estructura económica lleva a concluir que el trabajador extranjero que desarrolla su actividad en nuestra región muestra una menor cualificación profesional que el trabajador extranjero del resto del país. Los datos indican que existe una mayor preparación teórica y profesional de los extranjeros a nivel nacional. Los extranjeros de La Rioja trabajan principalmente en la construcción, en la industria y como peones en la agricultura, trabajos para los que no es necesaria una formación profesional muy especializada. En La Rioja los puestos que requieren una capacitación técnica o los de administración y dirección son escasos y por ello muy inferiores a los del total español. 
En paralelo al aumento poblacional extranjero se observa un mayor crecimiento de afiliados a la Seguridad Social en La Rioja con respecto al resto de España. Estos datos señalan que se trata de una región especialmente receptiva a la inmigración laboral y que desde el año 2000 ha demandado y ofrecido mano de obra al extranjero. Desde 2008, año en el que ya se hace patente la disminución de afiliaciones a la Seguridad Social en el país, la caída es mayor entre los extranjeros, caída que se acentúa en La Rioja. Por otra parte los datos riojanos manifiestan una clara masculinidad de la inmigración laboral riojana, que se corrobora con los datos sobre contrataciones; es importante destacar que en La Rioja, en 2008 , tras varios años de presencia inmigrante, el 70,9\% de las contrataciones se hicieron a hombres, y tan solo el 29,1\% a mujeres, índices más extremos que en el resto de España. En cuanto a las nacionalidades destaca sin duda el colectivo rumano y el marroquí.

Al igual que en el resto del país y de nuevo debido a la particular demanda de mano de obra en España, el inmigrante riojano trabaja en su gran mayoría por cuenta ajena, siendo algunos sectores como el de las empleadas del hogar y el de los trabajadores del campo asalariados un ámbito copado de forma extraordinaria por ellos.

Los datos de contratación de extranjeros confirman los de las cotizaciones a la Seguridad Social. Se puede afirmar que la contratación de extranjeros tiene un peso mayor en La Rioja que en España y ese peso ha ido aumentando en mayor medida en nuestra región. Por otro lado una de las principales características de la contratación riojana a inmigrantes es su temporalidad. De los 39.222 contratos firmados con trabajadores extranjeros en 2008 , el 9I,4\% fueron temporales.

En La Rioja, durante estos años fue en el sector de los servicios en el que hubo un mayor nivel de contratación. El dato tiene especial relevancia si lo ponemos en relación con el porcentaje español, que alcanza un extraordinario 6I,2\% y que nos habla del gran peso que los servicios tienen en la contratación extranjera a nivel nacional debido al abandono de estos puestos de trabajo por el trabajador oriundo.

En cuanto al desempleo en La Rioja dos son los sectores que han afectado especialmente a los trabajadores extranjeros, el agrícola y la construcción. En el primero más de la mitad de los parados riojanos eran inmigrantes en 2008, en la construcción, sector especialmente afectado por la crisis, el porcentaje es menor aunque se aproxima también al cincuenta por ciento. Ambos destacan sobre la industria y los servicios, sectores con menor peso económico. Tanto en España como en La Rioja son los trabajos relacionados con la actividad constructiva e inmobiliaria los más afectados por la crisis económica pues sumando ambos llegan tanto en La Rioja como en España a porcentajes de desempleo que rondan el cincuenta por ciento. En cuanto a la edad de los parados extranjeros también se repiten los datos riojanos y españoles, siendo el tramo de entre 30 y 34 años el grupo más afectado. Y en cuanto a la nacionalidad, en La Rioja y en 2008 el grupo más numeroso de parados por continente de origen fue el de los africanos, siendo un tercio de los parados extranjeros riojanos.

Por otro lado en el caso riojano se observa que los extranjeros menos formados son los que han sufrido de forma más clara el período de crisis. En 2008 más de la mitad de los parados extranjeros riojanos no tenían estudios primarios completos. El dato varía con respecto a España, pues en todo el país es el colectivo de los extranjeros con estudios secundarios generales el que más ha sufrido la situación de paro, aunque también a nivel nacional han tenido un peso fundamental los extranjeros sin una formación primaria. Si tenemos en cuenta los porcentajes de paro extranjero, nuestra Comunidad Autónoma se encontraría dentro del grupo de comunidades con una mayor incidencia del paro inmigrante.

Se puede afirmar que en La Rioja los trabajadores españoles y extranjeros no compiten por unos mismos puestos de trabajo. La mano de obra inmigrante se caracteriza 
por una escasa preparación profesional, gran movilidad y dinamismo, mayor que la del trabajador nacional, y una clara precariedad en el empleo. El mercado laboral ha asignado al trabajador extranjero una serie de condiciones laborales y trabajos en sectores concretos diferentes al trabajador español.

Para concluir hay que destacar lo siguiente:

I.- La inmigración se debe considerar ya en España, y por tanto en La Rioja, como una cuestión estructural y está protagonizada por una motivación económica.

2.- La llegada de inmigrantes a España y especialmente a La Rioja ha generado riqueza económica, siendo la mano de obra extranjera complementaria a la riojana, por tener ésta un nivel de cualificación mayor. Se debe destacar el considerable impacto de la inmigración riojana en la economía regional siendo clave para su desarrollo.

3.- Los inmigrantes riojanos han venido en estos últimos años con intención de permanecer en nuestra región a pesar del inicio del periodo de crisis.

4.- A pesar de todo existe en la actualidad cierta incertidumbre sobre el comportamiento de la evolución de la inmigración debido al periodo económico en el que nos encontramos, si bien, a pesar de unas políticas favorecedoras, no se observa una significativa salida de inmigrantes de nuestra región con destino a sus países de origen.

\section{Bibliografía}

AGUILAR BENÍTEZ DE LUGO, M. Y GRIEDER MACHADO, H.C. (200I): «La reagrupación familiar de los extranjeros en España», El nuevo derecho de extranjería, Granada.

AJA, E. y ARANGO, J. (2007): «La inmigración en España en 2006», en AJA, E. y ARANGO, J. La inmigración en España en 2006. Anuario de inmigración y políticas de inmigración, Barcelona, CIDOB. p. I2.

BAYONA, J. (2008): «La población de nacionalidad extranjera en España: evolución y características demográficas», Entelequia 8, p. I34 y ss.

COLECTIVO IOÉ y FERNÁNDEZ, M. (20I0), Encuesta Nacional de Inmigrantes 2007: el mercado de trabajo y las redes sociales de los inmigrantes, Madrid: Ministerio de Trabajo e Inmigración.

CUADRADO ROURA, J.R., IGLESIAS FERNÁNDEZ, C. Y LLORENTE HERAS, R. (2007): Inmigración Y mercado de trabajo en España (1997-2005), Bilbao: Fundación BBVA, p. 2I-22.

LÁZARO GONZÁLEZ, I. (2002): «La reagrupación familiar de los extranjeros en España. Previsible incidencia de la futura Directiva sobre el derecho de reagrupación familiar», Migraciones I2, p. 43 y ss.

MOLINER NAVARRO, R.M. (200I): «Reagrupación familiar y modelo de familia en la LO 8/2000 de derechos y libertades de los extranjeros en España», AC i4, p. 487 y ss.

- (2004): «El concepto de familia nuclear en la Directiva europea 2003/86/CE sobre reagrupación familiar», Revista jurídica de igualdad de oportunidades entre hombres y mujeres, Aequalitas I5, p. 7 y ss.

MOYA ESCUDERO, M. (200I): «Derecho a la reagrupación familiar», en VV.AA., Comentario sistemático a la Ley de Extranjería, Granada.

OLIVER ALONSO, J. (2007): «Inmigración y mercado de trabajo en 2006: razones de la acentuación del choque inmigratorio», en AJA, E. Y ARANGO, J. (eds.), La inmigración en España en 2006. Anuario de inmigración y políticas de inmigración, Barcelona: CIDOB, p. 46.

PAJARES, M. (2007), Inmigración y mercado de trabajo. Informe 2007, Madrid: Ministerio de Trabajo e Inmigración.

- (2010): Inmigración y mercado de trabajo. Informe 2010, Madrid: Ministerio de Trabajo e Inmigración, p. I9.

QUIRÓS FONS, A. (2008): La familia del extranjero. Regímenes de reagrupación e integración, Valencia: Tirant lo Blanch.

ROMERO VALIENTE, J.M. (2003): «La migración dominicana hacia España, factores, evolución y desarrollo», Revue européenne des migrations internationales I9, $\mathrm{n}^{\circ} \mathrm{I}$. 
SANTOLAYA MACHETTI, P. (2004): El derecho a la vida familiar de los extranjeros, Valencia: Tirant lo Blanch.

VARGAS GÓMEZ-URRUTIA, M. (2006): La reagrupación familiar de los extranjeros en España, Pamplona: ed. Aranzadi.

ZABALO ESCUDERO, E. (2008): «Relaciones internacionales de familia y el derecho de los extranjeros a vivir en familia», Revista de Derecho Migratorio y Extranjería I8. 